\title{
Plant-derived silica nanoparticles and composites for biosensors, bioimaging, drug delivery and supercapacitors: a review
}

\author{
S. Prabha ${ }^{1}$ (D) D. Durgalakshmi ${ }^{1}$ (D) Saravanan Rajendran ${ }^{2} \mathbb{D} \cdot$ Eric Lichtfouse $^{3,4} \mathbb{D}$
}

Received: 14 April 2020 / Accepted: 17 October 2020 / Published online: 12 November 2020

(c) Springer Nature Switzerland AG 2020

\begin{abstract}
Silica nanoparticles have rapidly found applications in medicine, supercapacitors, batteries, optical fibers and concrete materials, because silica nanoparticles have tunable physical, chemical, optical and mechanical properties. In most applications, high-purity silica comes from synthetic organic precursors, yet this approach could be costly, polluting and non-biocompatible. Alternatively, natural silica sources from biomass are often cheap and abundant, yet they contain impurities. Silica can be extracted from corn cob, coffee husk, rice husk, sugarcane bagasse and wheat husk wastes, which are often disposed of in rivers, lands and ponds. These wastes can be used to prepare homogenous silica nanoparticles. Here we review properties, preparation and applications of silica nanoparticles. Preparation includes chemical and biomass methods. Applications include biosensors, bioimaging, drug delivery and supercapacitors. In particular, to fight the COVID-19 pandemic, recent research has shown that silver nanocluster/silica deposited on a mask reduces SARS-Cov-2 infectivity to zero.
\end{abstract}

Keywords Silica nanoparticles $\cdot$ Structure $\cdot$ Biomass $\cdot$ Rice husk $\cdot$ Sugarcane bagasse $\cdot$ Corn cob $\cdot$ Synthesis $\cdot$ Applications $\cdot$ Theranostic $\cdot$ Supercapacitor

\section{Introduction}

Silicon is a major element of earth's crust. Silica sand, the primary ore source of silicon, is abundant and easy to process. Silica minerals are referred by quartzite, tridymite,

D. Durgalakshmi

durgaklakshmi@gmail.com

S. Prabha

spriyadharshni12@gmail.com

Saravanan Rajendran

Saravanan3.raj@gmail.com

Eric Lichtfouse

eric.lichtfouse@gmail.com

1 Department of Medical Physics, Anna University, Chennai 600025, India

2 Departamento de Ingeniería Mecánica, Facultad de Ingeniería, Universidad de Tarapacá, Avda. General Velásquez, 1775 Arica, Chile

3 Aix-Marseille Univ, CNRS, IRD, INRAE, Coll France, CEREGE, Avenue Louis Philibert, 13100 Aix en Provence, France

4 International Research Centre for Renewable Energy, State Key Laboratory of Multiphase Flow in Power Engineering, Xi' an Jiaotong University, Xi' an 710049, China metamorphic rock, cristobalite and minerals such as polymorphs of silica. The combination of silicon and oxygen is called silicate, and $90 \%$ of earth's crust is made of silicate minerals. Clays and silica sand are silicate minerals that are used in applications such as making Portland cement in building mortar and modern stucco. Concrete made of silicates integrated within silica sand for making concrete is a major building material (Greenwood and Earnshaw 1997). Silicones are used for various products such as moldrelease agents, molding compounds, waxes, waterproofing treatments, mechanical seals and high-temperature greases. Silica in the form of clay and sand is used in bricks and concrete. Glass silica obtained from sand is the major element in making various glass material with diverse properties. The silly putty contains also substantial amounts of silica, it is made by addition of boric acid to silicone oil. Liquid silicone is widely used as dry cleaning solvent and is an alternative for perchloro-ethylene solvents (Koch and Clément 2007). 
Silica is also used in biomedical applications such as contact lenses, breast implants, explosives and pyrotechnics.

Nanotechnology involves the development of nano-sized materials and devices. Notably, silica nanoparticles have occupied the prime position due to their facile synthesis, rich surface chemistry, low toxicity and controllable properties such as optoelectronic, mechanical and chemical stability (Rossi et al. 2005; Vivero-Escoto and Huang 2011). These properties are not only extensively considered in biomedical field and but also for diverse applications such as agricultural, food industries, photovoltaic and energy storage applications (Liberman et al. 2014; Devi and Balachandran 2016). Nanotechnology enables the extension of multifunctional medicine by integrating materials that allow multimodal imaging and theranostics applications (Bharti et al. 2015). Notably, mesoporous silica nanoparticles have uniform pore size, hydrophilic surface property and high surface area. Such properties increase electrochemically active centers, thus enhancing electron transport and promoting electrolyte penetration, which meets the requirements of next-generation supercapacitors (Huang et al. 2013).

Silica nanoparticles have also been applied for fighting COVID-19. Here, a nanocomposite of silver nanocluster/ silica deposited on a FFP3 mask reduces the SARS-Cov-2 to zero (Balagna et al. 2020). The nanocomposite also increases the life time of the mask and improves air filtering. Morevover, silica nanoparticles can be transformed to have a superhydrophilic surface which repels contaminated droplets (Meguid and Elzaabalawy 2020).

Natural resources-based silica has garnered considerable interest in the materials science and biomedicine fields owing to its low cost, eco-friendliness, bioactivity and availability. Biomass is an alternative source for widely used organic precursors, namely tetraethyl orthosilicate (TEOS) and tetramethylorthosilicate. In biomedical applications, stability and biocompatibility are the prime issues. Therefore research if focussing on the development of biomass for preparing silica and implemented to theranostics applications.

Developed countries have followed the concept by which waste materials are not really waste but new sources for creating new materials. Developing countries have abundant agriculture-based resources and their by-products are used to produce various low-value products. In 2005, a bioenergy production project using municipal, animal, agricultural and industrial wastes was assigned by five countries: India, China, Sri Lanka, Philippines and Thailand. As a result, in 2010 , bioenergy represented $45 \%$ of total energy in India, 17\% in China, 33\% in Sri Lanka, 34\% in Philippines and $14 \%$ in Thailand. India is the major energy consumer in Asia. During 2011, biomass gasifier assignment of 0.5 MW power in Tamil Nadu and 1.20 MW in Gujarat were successfully installed (Pode and Reviews 2016).
In India, 120 million tons of paddy rice is produced per annum, giving nearly 4.4 tons of rice husks (Giddel and Jivan 2007). High silica content has been observed in biomass wastes (Oladeji 2010; Shen et al. 2014; Zemnukhova et al. 2015; Hossain et al. 2018; Dhinasekaran et al. 2020). Rice husk ash contains 83-98\% of silica (Saxena et al. 2009; Babaso and Sharanagouda 2017). Corn is another major crop plant with 785 million tons produced annually in this world. India is the seventh largest producer of corn cob, with silica content as high as $60 \%$ in biomass (Kumar et al. 2010). India produces an average of 500 million tons of crop residue per year, of which 140 million tons is surplus and 92 million tons is left as burned (Bhuvaneshwari et al. 2019). Globally, uncontrolled burning of biomass wastes is causing environmental and health issues, thus calling for recycling options.

Recent research on silica has focused on nanoparticles. Silica nanoparticles can be prepared from either organic chemicals or biomass. Comparatively, the usage of biomass is less compared to synthetic organic precursors due to lack of a review and assessment on the importance of silica in biomass. Many reports have reviewed the preparation of silica nanoparticles from pure organic chemicals (Wu et al. 2013a, b; Bleta et al. 2018; Morin-Crini et al. 2019; Meena et al. 2020; Mahajan et al. 2020). Here we focus on silica nanoparticles from biomass for biosensors, bioimaging, drug delivery and supercapacitor applications.

\section{Structural properties of silica minerals}

\section{Crystalline and amorphous structure}

Solid materials are generally crystalline, made of atoms, molecules and ions arranged in an orderly repeating pattern. In amorphous materials, atoms are not arranged in orderly repeating patterns. Silica has two types of structures: crystalline and amorphous. Silica occurs naturally as the solid amorphous phase of flint and opal and as the crystalline phase of cristobalite, quartz and tridymite. Amorphous phases can be transformed into crystalline phases by thermal treatments (Eq. (1)) (Waddell 2000).

Quartz $\stackrel{870^{\circ} \mathrm{C}}{\longleftrightarrow}$ Tridymite $\stackrel{1470^{\circ} \mathrm{C}}{\longleftrightarrow}$ Cristoblite $\stackrel{1710^{\circ} \mathrm{C}}{\longleftrightarrow}$ Melting point

Quartz and sandstone are the impure forms of silica. The crystalline phases of silica are melanophlogopite, $\alpha$-quartz, $\alpha$-cristobalite, $\beta$-quartz, $\beta$-cristobalite, $\gamma$-tridymite, $\beta$-tridymite, $\alpha$-tridymite, fasriges, chalcedon, keatite, moganite and stishovite. Amorphous phases of silica include hyalite opal, natural silica glass, sintered pearl, lechatelierite are amorphous phases of silica (Fanderlik 2013). There are three polymorphic structures present in the silica, each structure having both low-temperature $(\alpha)$ and a high-temperature 
Crystalline $\mathrm{SiO}_{2}$

(Quartz)

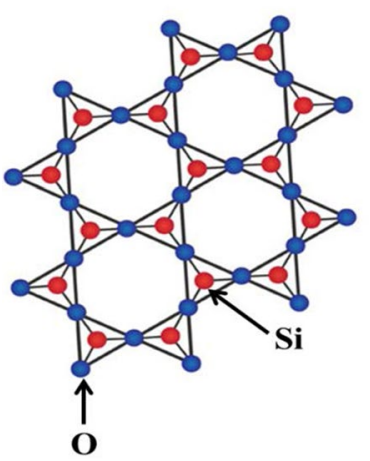

Amorphous $\mathrm{SiO}_{2}$

(Glass)

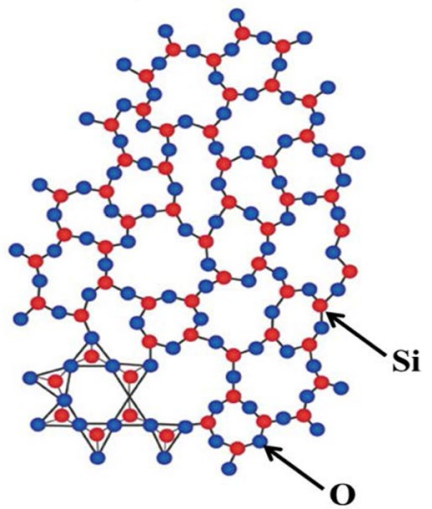

Fig. 1 Structure of crystalline and amorphous silica

$(\beta)$ forms (Douglas and Ho 2006). In sediments, the transformation of amorphous silica opal-A into crystalline opal-CT (cristobalite-tridymite) with increasing burial, temperature and pressure has been correlated with an abrupt transformation of organic matter (Lichtfouse and Rullkötter 1994).

Figure 1 shows the structure of both crystalline and amorphous silica structures.

\section{Silica and silicones}

In 1800, Sir Humphry Davy thought that silica has to be a compound and not a single element. To test this hypothesis, in 1808 he did experiments to decompose of silex, alumine and glucine zircone, yet he failed to isolate the Si metal. In 1811, Louis-Jacques Thenard (1777-1857) and LouisJoseph Gay-Lussac (1778-1850) explained that heating potassium with silicon tetrafluoride results in the formation of impure amorphous silicon. Silicon was discovered by Jakob Berzelius (1779-1848); in 1824, he prepared amorphous silicon successfully using earlier methods, and then, he removed fluorosilicates by repeated washing to get the purified product. The name silica is coming from the Latin word silex. Silica is the combination of silicon $(\mathrm{Si})$ with oxygen $\left(\mathrm{O}_{2}\right)$ and the most plentiful compound in the earth's crust (Pauling 1957; Holden 2001). The covalent network structure of $\mathrm{SiO}_{2}$ is given in Fig. 2 .

Among all polymers, organic groups attached to a chain of inorganic atoms is a unique properties of silicone. Silicones are used in of electronics, paints, construction and beverages (Korzhinsky et al. 1995). In medicine, silicone is used in artificial joints, antacids, implants of various notoriety and pacemakers (Korzhinsky et al. 1995). Silicon dioxide (silica) occurs in the form of sand. Reduction of silica with carbon at high temperature was performed for manufacturing
Fig. 2 Possible covalent network structure of silica- $\mathrm{SiO}_{2}$

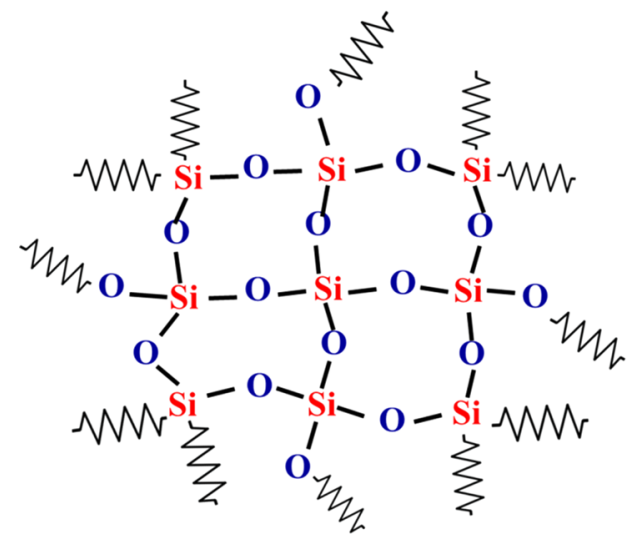

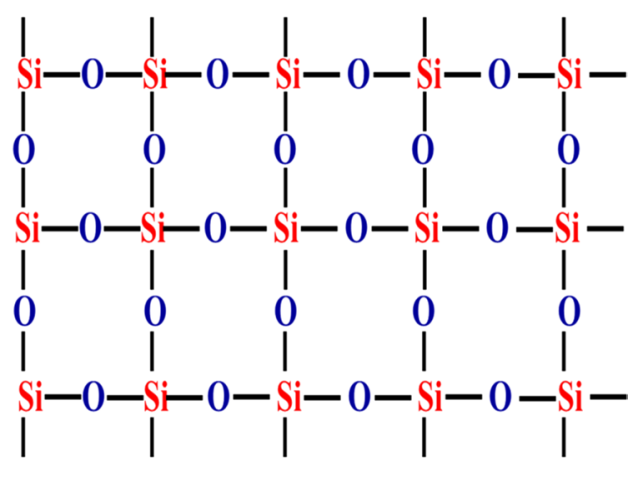

Fig. 3 Molecular structural arrangements of silicones

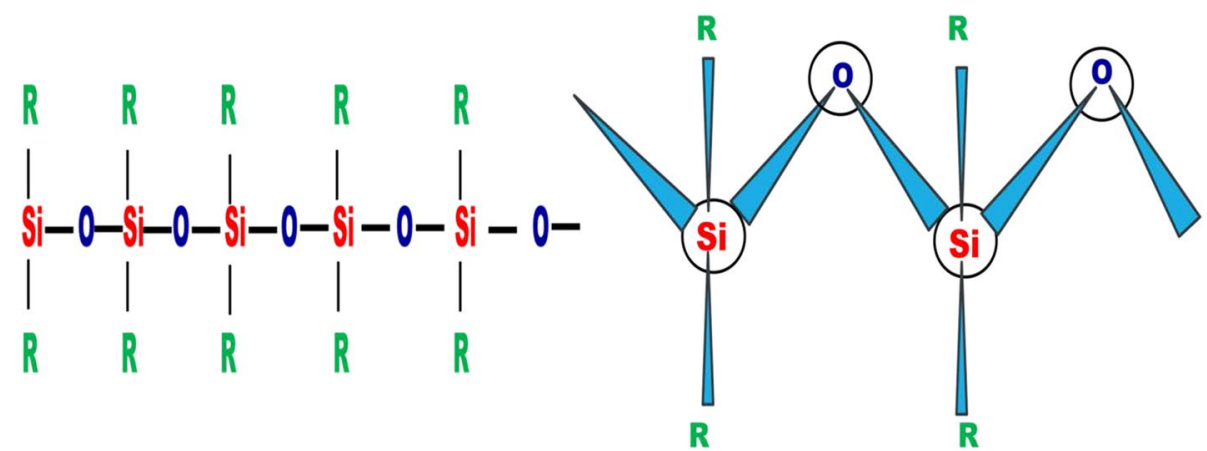




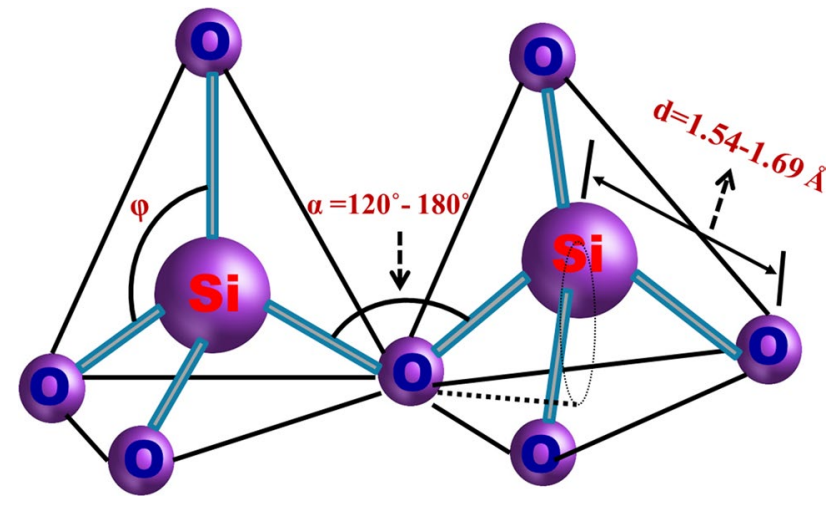

Fig. 4 3D schematic of the regular silica structure. Modified after Salh (2011)

silicone (Eq. (2), Bell et al. 1968; Mozzi and Warren 1969; Gerber and Himmel 1986; Korzhinsky et al. 1995).

$\mathrm{SiO}_{2}(\mathrm{~s})+2 \mathrm{C}(\mathrm{s}) \rightarrow \mathrm{Si}(\mathrm{s})+2 \mathrm{CO}(\mathrm{g})$

The $\mathrm{SiO}_{4}$ tetrahedron is the central functional component of both amorphous and crystalline of silica. The silicon atom is placed at the center, and the four oxygen atoms are connected at each side of a tetrahedron (Fig. 3, Henderson and Baker 2002). According to various forms of silica, the tetrahedron depends on the angle $(\alpha)$ and bond length.

The energy of the $\mathrm{Si}-\mathrm{O}$ bond is $4.5 \mathrm{eV}$ (Devine et al. 2000). Figure 4 shows the 3D silica structural parameters of bond length (d), polyhedron angle $(\varphi)$ and inter-tetrahedral bond angle $(\alpha)$ (Lide 2004).

In Raman spectra, bands correspond to $\mathrm{Si}-\mathrm{O}^{-}$groups of various $Q^{n}$ units $(n<4)$. The band at $1050-1100 \mathrm{~cm}^{-1}$ is due to the symmetric stretching vibrations of the $\mathrm{SiO}_{4}$ tetrahedra with one nonbridging oxygen $(\mathrm{NBO})$ atom $\left(Q^{3}\right.$ units); $920-950 \mathrm{~cm}^{-1}$ is due to the $\mathrm{Si}-\mathrm{O}^{-}$stretching with two NBO ( $Q^{2}$ units); $900 \mathrm{~cm}^{-1}$ is attributed to the stretching vibration of $Q^{1}$ units with three nonbridging oxygens; and $850 \mathrm{~cm}^{-1}$ is due to the symmetric stretching mode of $Q^{0}$ anions (McMillan 1984). Figure 5a shows the infrared bands with vibrational modes. Nuclear magnetic resonance (NMR) study also predicts $\mathrm{Q}^{0}, \mathrm{Q}^{1}, \mathrm{Q}^{2}, \mathrm{Q}^{3}, \mathrm{Q}^{4}$ notation in silica, and the numbers $0-4$ denote the number of ' $\mathrm{Si}$ ' units connected through the oxygen to the other single silicon atom. $\mathrm{Q}^{0}, \mathrm{Q}^{1}$, $\mathrm{Q}^{2}, \mathrm{Q}^{3}$ are referred to as a silicon atom with zero, one, two

\section{$2 Q^{n} \leftrightarrow Q^{n-1}+Q^{n+1}(n=1,2,3)$}

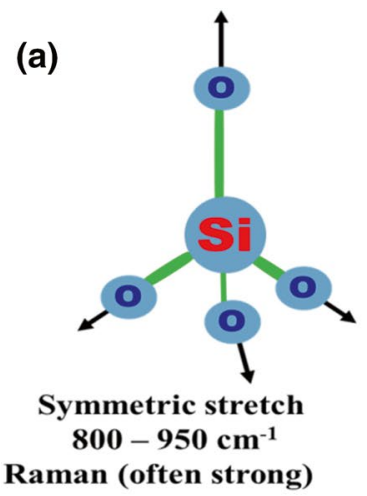

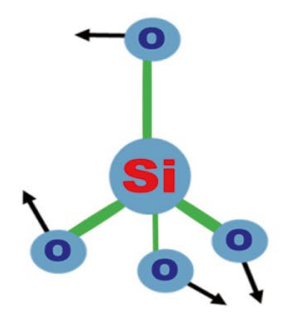

Symmetric bend $300-500 \mathrm{~cm}^{-1}$ present in Raman

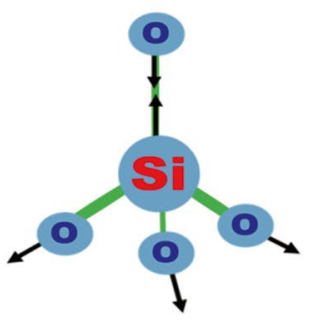

Assymmetric stretch $850-1200 \mathrm{~cm}^{-1}$ Infrared (strong), Raman

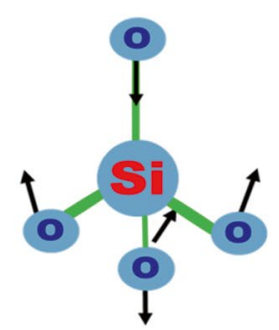

Assymmetric bend $400-600 \mathrm{~cm}^{-1}$ Infrared, Raman

(b)
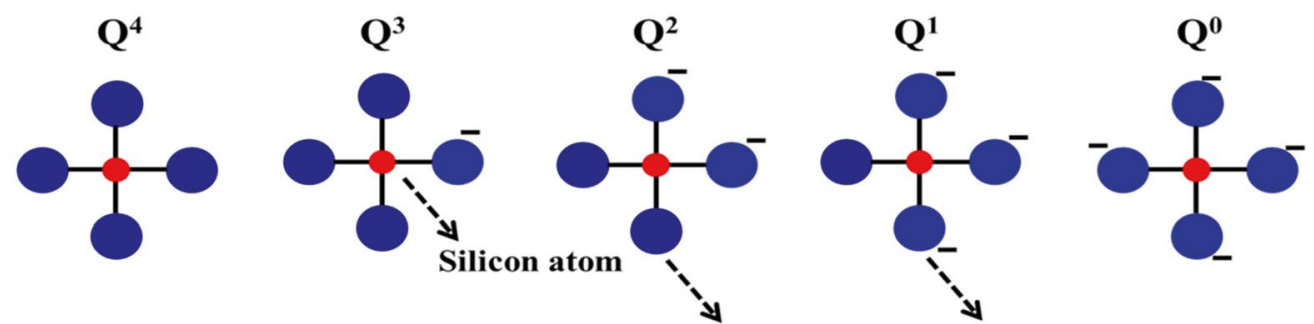

Bridging oxygen atom

Nonbridging oxygen atom

Fig. 5 a Major vibrational modes for a nonlinear group. b 2D Representation of $\mathrm{Q}^{\mathrm{n}}$ species. Modified after Salh (2011) and Osipov et al. (2015) 
and three attachments of another silicon atom, respectively (Lunevich et al. 2016). A schematic two-dimensional representation of the $Q^{n}$ species is shown in Fig. 5b.

$2 \mathrm{Q}^{n \rightarrow} \leftrightarrow \mathrm{Q}^{n-1}+\mathrm{Q}^{n+1}(n=1,2,3)$

\section{Preparation of silica nanoparticles}

Various preparation methods are available to synthesize silica nanoparticles, such as microemulsion processing (Finnie et al. 2007), chemical vapor deposition (Rezaei et al. 2014), combustion synthesis (Yermekova et al. 2010), plasma synthesis (Saito et al. 2018), hydrothermal techniques (Gu et al. 2012) and sol-gel processing (Prabha et al. 2019). Major researches efforts have focused on controlling the size and morphology of nanoparticles (Brinker and Scherer 2013). During chemical vapor condensation (CVC), inorganic precursors, e.g., silicon tetrachloride $\left(\mathrm{SiCl}_{4}\right)$, are decomposed by a high-temperature flame or react with hydrogen and oxygen to yield silica nanoparticles (Silva 2004; Vansant et al. 1995). The main drawback of flame synthesis is the difficulty in controlling the phase composition, particle size and morphology (Klabunde 2001), yet flame synthesis is the major method for producing silica nanoparticles commercially in powder form. The different methods for silica nanoparticle preparation are presented in Table 1 .

\section{Chemical method}

The sol-gel technique has advantages of yielding pure, homogeneous materials, and enabling to obtain various forms of materials such as fibers, films, submicron powders and monoliths (Fardad 2000; Brinker and Scherer 2013). The sol-gel process is defined as the chemical transformation from colloidal suspension of sol into a 3D interconnecting network of gel. In this process, a metal alkoxide undergoes hydrolysis and polymerization reactions to form the sol. Further, the sol allows to preparing the materials in various forms such as discrete particles or polymers. The reaction is controlled by the reactants such as alcohol, water and acid/base; the size of the particles is tuned by $\mathrm{pH}$, precursor concentration and temperature (Burda et al. 2005; Yu et al. 2008; Singh et al. 2011a).

Silica nanoparticles are synthesized by the sol-gelassisted, low-temperature Stöber method. In this process, the hydrolytic condensation reaction of $\mathrm{Si}-\mathrm{OH}$ coupling occurs by replacement of an alkoxide group (-OR) with a hydroxyl group (-OH) (Kim et al. 2017). In the beginning, Stöber et al. prepared $1 \mu \mathrm{m}$ of silica nanoparticles using the sol-gel method (Stöber et al. 1968). Then, a hundred nanometers to a few micrometers silica nanoparticles were obtained by controlling the concentration of the precursor during hydrolysis (Bogush et al. 1988). The Stöber method also allowed to synthesize various shapes of silica nanoparticles such as nanocubes and spheres. The cubic shape of silica nanoparticles is obtained by addition of tartaric acid during synthesis (Yu et al. 2005), whereas monodisperse nanocubes of silica nanoparticles are prepared using ammonium tartrate as a surface-specific template in the sol-gel method (Yu et al. 2005).

The influence of synthesis parameters on the size and shape of silica nanoparticles has been largely studied. The concentration of the precursor, e.g., tetraethylorthosilicate, and the alcohol, e.g., ethanol, both control the size and distribution of silica nanoparticles. Particle sizes of $1.5 \mathrm{~nm}$ and $20-1000 \mathrm{~nm}$ were obtained by tuning the concentrations of alcohol and the precursor (Shimura and Ogawa 2007; Wang et al. 2010). Reaction temperature and time, and rotation per minute are also controlling the homogeneous distribution (Dabbaghian et al. 2010). Particle sizes of $50-800 \mathrm{~nm}$ and $32-300 \mathrm{~nm}$ were obtained by varying the reaction temperature and time (Novak et al. 2010; Kim et al. 2017). Narrow particles can be obtained by controlling the reaction parameters in the Stöber method.

In the wet chemical synthesis, the surfactant allows to tune the size of the particle and prevent agglomeration. Amorphous silica nanoparticles of 300-400 nm were prepared using polyvinyl pyrrolidone, cetyltrimethylammonium bromide (CTAB) and sodium dodecyl sulfate (Stanley and Nesaraj 2014). Particle size of $9 \mathrm{~nm}$ was obtained using polyethylene glycol-100 as a surfactant (PEG 1000, Guo et al. 2017). The properties of silica nanoparticles can be tuned also during sol-gel-assisted sonication. Particle size decreases with increased concentration of reagents, e.g., $\mathrm{NH}_{3}$, tetraethylorthosilicate, ethanol and water, by ultrasonication during the sol-gel process (Rao et al. 2005). Further functionalization of silica nanoparticles allows applications in nanomedicine and the industry (Liberman et al. 2014; Dubey et al. 2015).

The main parameters controlling the size and shape of silica nanoparticles are concentrations of tetraethylorthosilicate (TEOS), ammonia hydroxide $\left(\mathrm{NH}_{4} \mathrm{OH}\right) /$ ammonia $\left(\mathrm{NH}_{3}\right)$, water, ethanol and reaction temperature (Bogush et al. 1988; Rao et al. 2005). Table 2 presents factors controlling particle size. Overall, particle size increases with tetraethylorthosilicate concentration (Sumathi and Thenmozhi 2016), ethanol concentration (Singh et al. 2014a), $\mathrm{pH}$ of the reaction (Singh et al. 2011a) and reaction temperature (Zainala et al. 2013). Particle size also increases with increasing concentration of $\mathrm{H}_{2} \mathrm{O}$, yet as $\mathrm{H}_{2} \mathrm{O}$ concentration increases the size of some particles decreases. This is because $\mathrm{H}_{2} \mathrm{O}$ accelerates tetraethylorthosilicate 
Table 1 Methods for preparation of silica nanoparticles

\begin{tabular}{lll}
\hline Methods & Synthesis & Observation \\
\hline Chemical method & Sol-gel & $\begin{array}{c}\text { Hydrolysis and condensation of metalalkoxides and inorganic } \\
\text { salts such as tetraethylorthosilicate and sodium silicate with } \\
\text { acid or base as catalyst } \\
\text { Prepared spherical shape of } 7-200 \mathrm{~nm}\end{array}$ \\
& & Sizes tuned by temperature, reagent concentration and pH \\
& & Lower time of reaction \\
& Wet chemical & Same reagents as sol gel method plus surfactants such as \\
& & polyvinyl pyrrolidone, \\
& & cetyltrimethylammonium bromide, sodium dodecyl sulfate \\
& & Amorphous product \\
& & Surfactant used to tune size \\
Biomass & Longer reaction time \\
& Precipitation & Silica gel made using sodium hydroxide and sulfuric acid \\
& Spherical particles 50 nm size
\end{tabular}

Mesoporous silica Soft templating method

Single micelle-templating

Vesicle-templating

Micro-emulsion-templating

Hard templating method

Polymer latex-templating

Metal or metal oxide nanoparticles
Mesoporous silica increases loading capacity in drug delivery Organosilica and ethylene-bridged organosilica precursors Pluronic triblock, pluronic F127 block and cationic block copolymer as templates

Mixture of silicates and silanes as anionic co-surfactants and cationic surfactants

Requires uniform particles size of $25-105 \mathrm{~nm}$ obtained by co-condensation

Tetraethylorthosilicate (TEOS) and organotriethoxysilanes in alkaline solution. Cationic surfactant: cetyltrimethylammonium chloride

Emulsion obtained by mixing oil, water, surfactant and alkaline solution

Thermally stable particles obtained using water, cationic surfactants and hydrocarbons

Mono-dispersed mesoporous silica nanoparticles obtained using polymer lattices, metal oxides and silica colloids

Selective functional groups activated by surface activation for silicification

Functional groups activation achieved by layer-by-layer deposition through electrostatic attraction

Cetyltrimethylammonium bromide (CTAB) acts both as stabilizer and mesostructural directing agent

Thickness of mesoporous silica shells tuned by varying the ratio of surfactant and silica precursor

Core is coated with non-toxic material to make nanoparticles biocompatible

Shell layer reduces toxicity and enhances the properties of the core material hydrolysis; and $\mathrm{H}_{2} \mathrm{O}$ dilute oligomers in the reaction, which helps to produce larger particles and smaller particle, respectively (Wang et al. 2010). Finally, a narrow distribution of particle size is obtained at high concentrations of ammonia (Zeng et al. 2015). While the mechanism corresponding to the nucleation and growth of silica nanoparticles still needs to be explained, a well understanding of the impact of synthesis parameters on the resultant particle size and shape is gradually developing.

Table 3 shows chemical methods of silica nanoparticle preparation. The influence of the chemical reagents on particle size, distribution and morphology is given as scanning electron microscopy and transmission electron microscopy images in Figs. 6 and 7, respectively. 
Table 2 Parameters controlling particle size of silica nanoparticles (Rao et al. 2005)

\begin{tabular}{|c|c|c|c|c|c|c|}
\hline \multirow[t]{2}{*}{ Parameter } & \multicolumn{5}{|c|}{ Experimental condition } & \multirow[t]{2}{*}{ Size $(\mathrm{nm})$} \\
\hline & $\begin{array}{l}\text { Ethanol } \\
(\mathrm{mol} \\
\left.\mathrm{L}^{-1}\right)\end{array}$ & $\begin{array}{l}\text { Tetraethylortho- } \\
\text { silicate (mol } \\
\mathrm{L}^{-1} \text { ) }\end{array}$ & $\begin{array}{l}\mathrm{H}_{2} \mathrm{O} / \text { tetraethyl- } \\
\text { orthosilicate (mol } \\
\mathrm{L}^{-1} \text { ) }\end{array}$ & $\mathrm{NH}_{4} \mathrm{OH}\left(\mathrm{mol} \mathrm{L}^{-1}\right)$ & Temp. $\left({ }^{\circ} \mathrm{C}\right)$ & \\
\hline Effect of ethanol & $4-8$ & 0.045 & 66.7 & 14 & - & $20.5<d<224.2$ \\
\hline Effect of tetraethyl orthosilicate (TEOS) & 8 & $0.012-0.11$ & $27-311$ & $\begin{array}{l}14 \\
14\end{array}$ & - & $60.1<d<417$ \\
\hline Effect of ammonia $\left(\mathrm{NH}_{4} \mathrm{OH}\right)$ & 8 & 0.045 & 66.7 & $2.8-28$ & - & $242.8<d<30.6$ \\
\hline Effect of water & 8 & 0.045 & $\begin{array}{l}66.7 \\
209\end{array}$ & 14 & - & $224.2<d<20.5$ \\
\hline Effect of temperature & $4-8$ & 0.045 & 66.7 & 14 & $\begin{array}{l}30 \\
70\end{array}$ & $116.0<d<462.03$ \\
\hline
\end{tabular}

Temp. Temperature, $d$ diameter

Table 3 Synthesis of silica nanoparticles by chemical methods

\begin{tabular}{|c|c|c|}
\hline Method & Observation & References \\
\hline $\begin{array}{l}\text { Stober: fixed ammonia }\left(\mathrm{NH}_{3}\right) / \mathrm{H}_{2} \mathrm{O} / \text { ethanol mole } \\
\text { amounts, varied mass of tetraethyl orthosilicate (TEOS) }\end{array}$ & Silica opals with diameters $480 \mathrm{~nm}$ and $540 \mathrm{~nm}$; & Razo et al. (2008) \\
\hline $\begin{array}{l}\text { Stober: TEOS: } 0.2 \mathrm{M}, \mathrm{NH}_{3}: 0.2 \mathrm{M}, \mathrm{H}_{2} \mathrm{O}: 1 \mathrm{M} ; \mathrm{NH}_{3} \text { : } \\
0.11 \mathrm{M} \text {, TEOS: } 0.28 \mathrm{M}, \mathrm{H}_{2} \mathrm{O}: 1 \mathrm{M} ; \mathrm{NH}_{3}: 0.3 \mathrm{M} \text {, TEOS: } \\
0.28 \mathrm{M}, \mathrm{H}_{2} \mathrm{O}: 1 \mathrm{M}\end{array}$ & $\begin{array}{l}\text { Particle size } 50 \mathrm{~nm}, 55 \mathrm{~nm}, 130 \mathrm{~nm} \text {, respectively. The } \\
\text { size of particles increased with increased tetraethyl } \\
\text { orthosilicate (TEOS) and ammonia }\left(\mathrm{NH}_{3}\right) \text { concentra- } \\
\text { tions. }\end{array}$ & Ibrahim et al. (2010) \\
\hline $\begin{array}{l}\text { Sonochemical sol-gel process. Polyethylene glycol } 1000 \\
\text { (PEG 1000) surfactant, tetraethyl orthosilicate (TEOS) } \\
\text { silicon sources \& ammonia }\left(\mathrm{NH}_{3}\right) \text { as a catalyst }\end{array}$ & $\begin{array}{l}\text { Disperse without any agglomeration. Equiaxed in shape. } \\
\text { Dispersity, size morphology tuned by varying PEG } \\
\text { 1000. Narrow size distribution of } 4-18 \mathrm{~nm} \text {. Average } \\
\text { size of } 9 \mathrm{~nm}\end{array}$ & Guo et al. (2017) \\
\hline $\begin{array}{l}\text { Stober method-silica nanoparticles with a high con- } \\
\text { centration.Tetraethylorthosilicate (TEOS) as a starting } \\
\text { material. }\end{array}$ & $\begin{array}{l}10 \mathrm{~nm} \text { of } 4 \% \text { of silica nanoparticle through reaction } \\
\text { condition. By removing solvent, particle concentration } \\
\text { increased up to } 15 \mathrm{wt} . \% \text { without aggregation }\end{array}$ & Tadanaga et al. (2013) \\
\hline $\begin{array}{l}\text { TEOS, ammonia }\left(\mathrm{NH}_{3}\right), \mathrm{H}_{2} \mathrm{O} \text { controls the reaction rate } \\
\text { and particle size. } \mathrm{NH}_{3} \text { and } \mathrm{H}_{2} \mathrm{O} \text { concentrations control } \\
\text { the hydrolysis and the condensation processes. }\end{array}$ & Monodisperse spherical silica nanoparticles at $20 \mathrm{~nm}$ & Beganskienè et al. (2004) \\
\hline Stober method & $\begin{array}{l}\text { A series of nanoparticles with controllable size from } 20 \\
\text { to } 100 \mathrm{~nm}\end{array}$ & \\
\hline $\begin{array}{l}\text { Silica nanoparticles influence as a function of the tem- } \\
\text { perature, precursor, water and catalyst }\end{array}$ & $\begin{array}{l}\text { Particle size is independent of the concentration of the } \\
\text { precursor and depends on the concentration of the } \\
\text { ammonia solution. But it is inversely proportional to the } \\
\text { reaction temperature }\end{array}$ & Qi et al. (2017) \\
\hline $\begin{array}{l}\text { Sol-gel method. Varied parameters, aging time } 2 \text { to } 6 \mathrm{~h} \text {. } \\
\text { Calcination temperature in the range of } 600{ }^{\circ} \mathrm{C}-700^{\circ} \mathrm{C}\end{array}$ & $\begin{array}{l}\text { Average size in the range of } 79.68 \mathrm{~nm} \text { to } 87.35 \mathrm{~nm} \text {. } \\
\text { Optimum conditions at calcination temperature of } 700 \\
{ }^{\circ} \mathrm{C} \text { and } 2 \mathrm{~h} \text { aging time }\end{array}$ & Azlina et al. (2016) \\
\hline $\begin{array}{l}\text { Micelles entrapment approach. Varying synthesis param- } \\
\text { eters }\end{array}$ & $\begin{array}{l}\text { The average size of silica nanoparticles depends on the } \\
\text { reactants and reaction temperature. The particle sizes of } \\
28.91 \mathrm{~nm}-113.22 \mathrm{~nm} \text { through varying the temperature } \\
\text { of the reaction. 2-butanol as a solvent }\end{array}$ & Hajarul et al. (2011) \\
\hline
\end{tabular}

\section{Biomass}

To prepare silica nanoparticles, most investigations use organic precursors of alkoxysilane such as tetraethylorthosilicate (TEOS) and tetramethylorthosilicate (Bosio et al.
2013). Nonetheless, silica from natural resources is used in biomedical and materials fields due to low cost, eco-friendliness and availability. Silica can be successfully extracted from biomass such as sugarcane bagasse, rice husk, corn cob, coffee husk and wheat husk. Rice husk is an abundant 

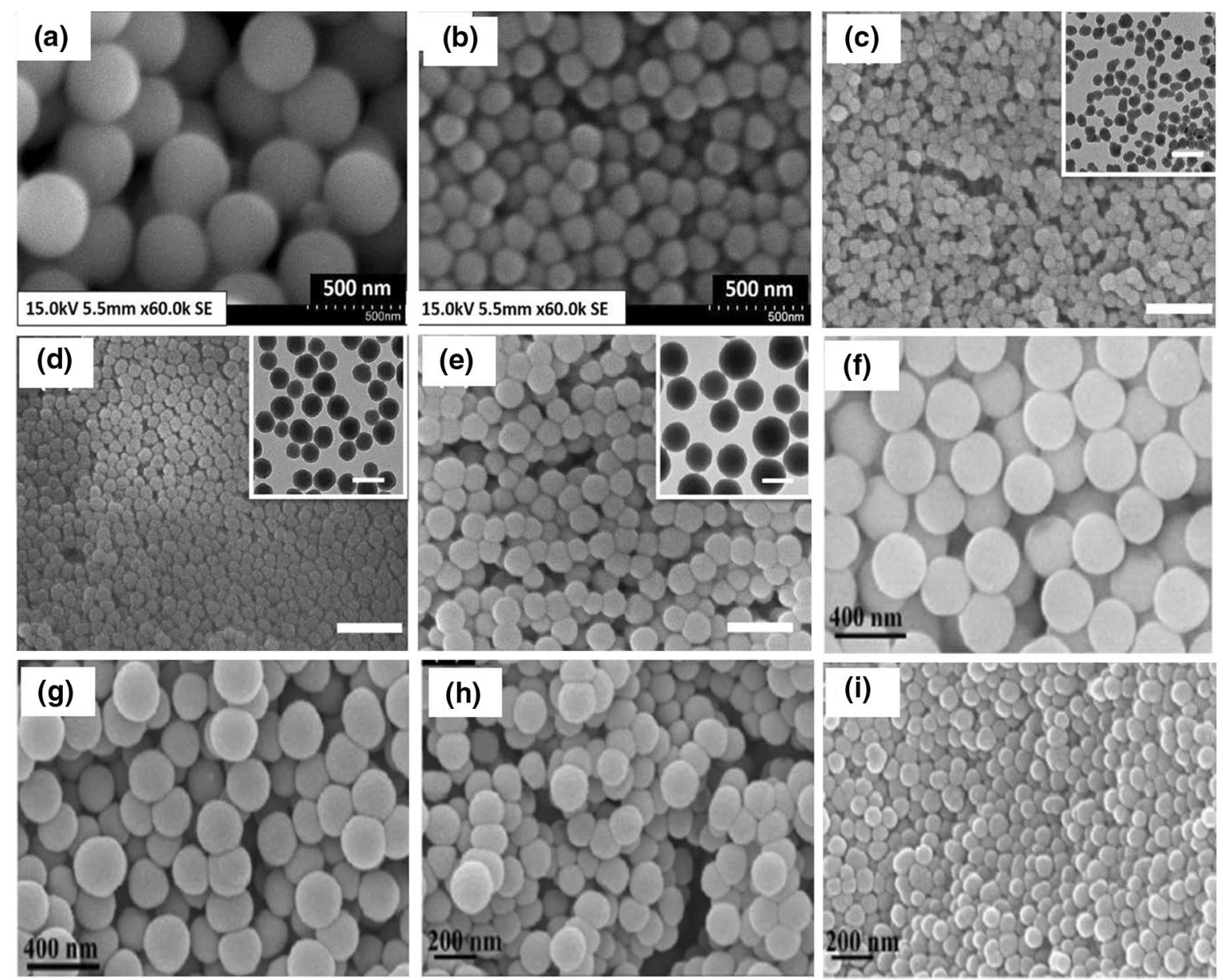

Fig. 6 Scanning electron microscopy (SEM) of silica nanoparticles with fixed concentration of tetraethylorthosilicate (TEOS) and varied ethanol to water ratios: a 4:1, b 3:1 (Prabha et al. 2019). Fixed concentration of TEOS, ethanol and water and varied $\mathrm{NH}_{3}$ concentrations: c $150 \mathrm{mM}$, d $200 \mathrm{mM}$, e $250 \mathrm{mM}$, reprinted with permission from Zhang et al. (2016). Fixed concentration of $\mathrm{NH}_{3}$ and ethanol

silicon source, and contains about $75-90 \%$ of cellulose, hemicellulose and lignin totaling and $17-20 \%$ of ash content (Azmi et al. 2016). The ash contains more than $90 \%$ of silica and few metallic impurities. Sugarcane bagasse ash, a major by-product of the sugarcane industry, contains $40-50 \%$ of silica; acid pretreatment allows to increase amount of silica up to $80 \%$ (Ganesan et al. 2007; Singh and All Jawald 2013).

Corn cobs, obtained from maize corn, contain more than $60 \%$ of silica (Owoeye et al.). Wheat husk ash contains up to $90 \%$ silica (Naqvi et al. 2011), which is close to that of dry silica sand, of 99.4\%. Bamboo leaf ash also has a large silica content of 75.90-82.86 wt.\% (Silviana and Bayu 2018). Raw teff straw contains about $52 \%$ of silica, which can be increased to $97 \%$ after thermal treatment (Wassie and Srivastava 2017). and varied $\mathrm{H}_{2} \mathrm{O}$ to TEOS ratio: f 8:4, g 10:4, h 12:4, i 14:4, reprinted with permission from Kim et al. (2017). Average particle sizes of a $450 \mathrm{~nm}, \mathbf{b} 200 \mathrm{~nm}$, c $30 \mathrm{~nm}$, d $50 \mathrm{~nm}$, e $90 \mathrm{~nm}$, f 280-300 nm, g 200_ $230 \mathrm{~nm}, \mathbf{h} 150-180 \mathrm{~nm}, \mathbf{i} 100-120 \mathrm{~nm}$. These images reveal that particle size increases with concentration of precursor, solvent and water

Examples of silica-rich biomass are shown in Fig. 8. Extraction of silica from biomass, preparation and characterization of silica nanoparticles are discussed below.

\section{Corn cob}

Corn is one of the most frequently grown food crops in the world; it is extracted from maize (corn). Corn cob ash contains more than $60 \%$ of silica and few metallic elements (Adesanya and Raheem 2009). Corn cob is grounded to a fine powder that is used to produce silica, silicates and silica nanoparticles. Corn cob is used for enzymes, absorbents (Tsai et al. 2001), proteins (Chen et al. 2007), fuel 

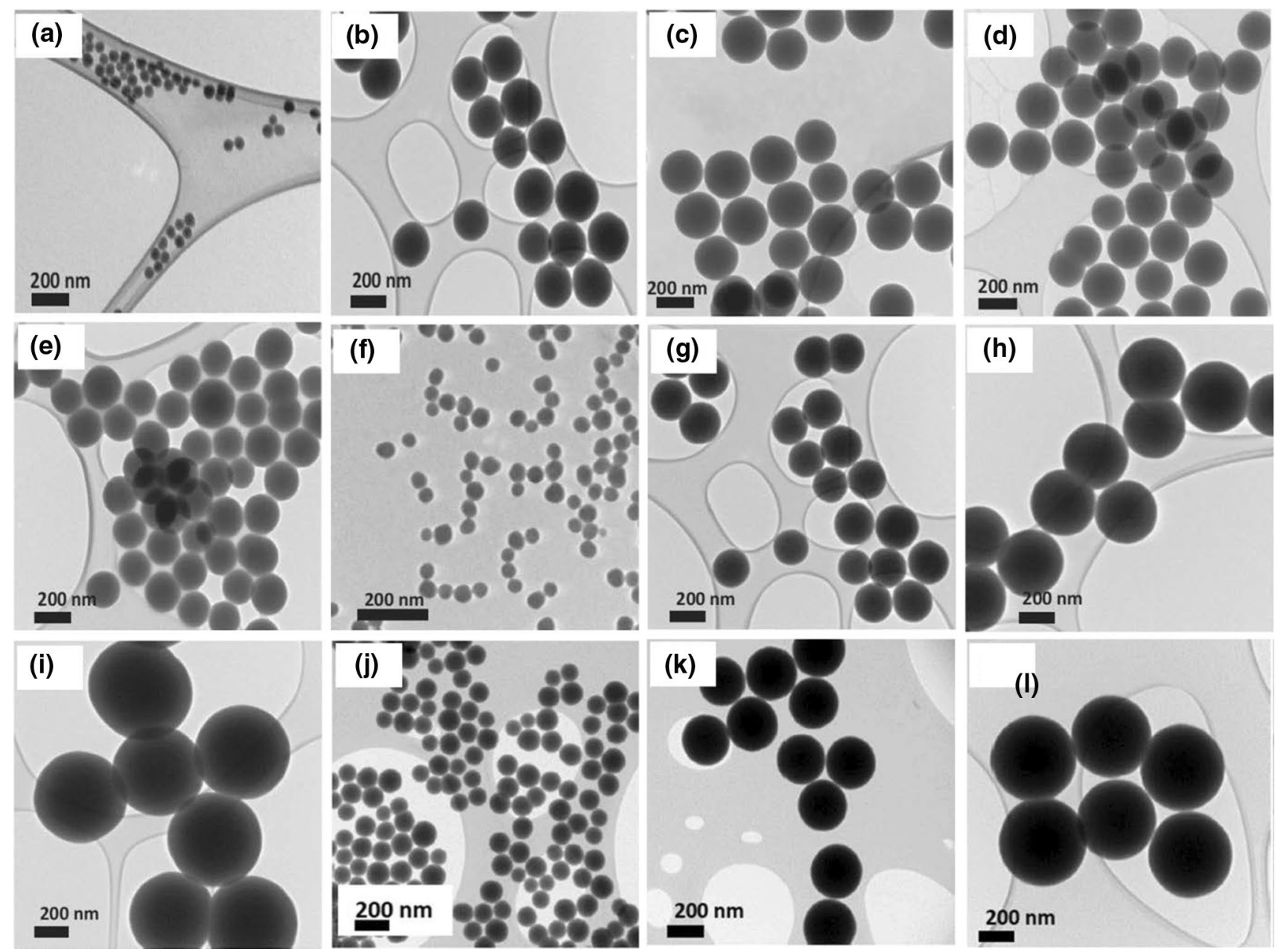

Fig. 7 Transmission electron microscopy (TEM) of silica particles. a-d fixed concentration of tetraethylorthosilicate (TEOS), ammonia solution $\left(\mathrm{NH}_{4} \mathrm{OH}\right)$ and varied amounts of water. Fixed concentration of TEOS and water, and varied concentration of $\mathrm{NH}_{4} \mathrm{OH} \mathbf{f} 0.11 \mathrm{M}, \mathbf{g}$ $0.28 \mathrm{M}, \mathbf{h} 0.57 \mathrm{M}, \mathbf{i} 1.13 \mathrm{M}, \mathbf{j} 0.17 \mathrm{M}, \mathbf{k} 0.40 \mathrm{M}, \mathbf{l} 0.85 \mathrm{M}$, reprinted

with permission from Greasley et al. (2016). $\mathrm{NH}_{4} \mathrm{OH}$ concentration controls the density of the silica particles. The narrow distribution of particle size obtained at higher ammonia concentration and $\mathrm{H}_{2} \mathrm{O}$ could accelerate TEOS hydrolysis and helps to produce larger particles
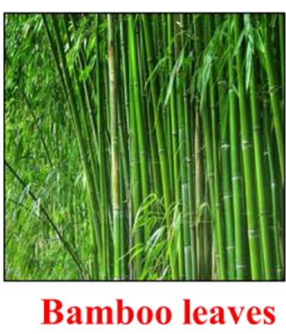

$>75.90-82.86$ wt. $\%$ of silica

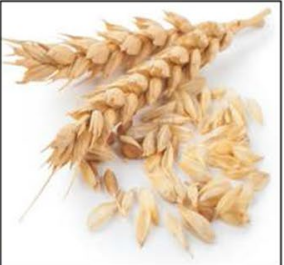

Wheat husk

$>49-99 \%$

of silica

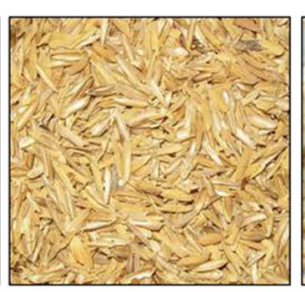

Rice husk

$>$ Higher than

$90 \%$ of silica

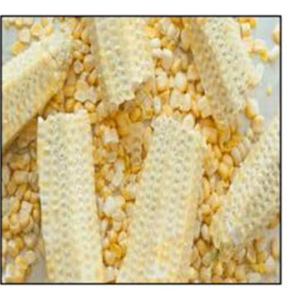

Corn cob

$>$ Higher than $60 \%$ of silica

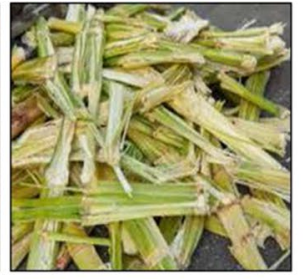

Sugarcane bagasse

$>40-50 \%$

of silica

Fig. 8 Biomass sources having high content in silica

(Kaliyan and Morey 2010) and cement (Adesanya and Raheem 2009). The chemical composition of raw corn cob ash and extracted silica is shown in Table 4 (Okoronkwo et al. 2013).
Nanosilica is prepared from corn cob ash by precipitation (Mohanraj et al. 2012). The 50-60\% of silica in corn cob ash must be purified to remove of impurities. Silica aquagel from corn cob ash is prepared by alkaline extraction and acid 
Table 4 Chemical composition of raw corn cob ash and extracted silica. Source: Okoronkwo et al. (2013)

\begin{tabular}{lcl}
\hline Constituent & $\begin{array}{l}\text { Raw corn cob ash } \\
(\text { wt. \%) }\end{array}$ & $\begin{array}{l}\text { Extracted } \\
\text { silica (wt. } \\
\%)\end{array}$ \\
\hline Silicon dioxide $\left(\mathrm{SiO}_{2}\right)$ & 47.66 & 97.13 \\
Aluminum oxide $\left(\mathrm{Al}_{2} \mathrm{O}_{3}\right)$ & 8.50 & 0.00 \\
Iron oxide $\left(\mathrm{Fe}_{2} \mathrm{O}_{3}\right)$ & 7.90 & 0.48 \\
Calcium oxide $(\mathrm{CaO})$ & 17.70 & 0.89 \\
Magnesium oxide $(\mathrm{MgO})$ & 7.20 & 0.92 \\
Sulfur trioxide $\left(\mathrm{SO}_{3}\right)$ & 0.70 & 0.00 \\
Manganese oxide $\left(\mathrm{MnO}_{2}\right)$ & 2.20 & 0.00 \\
Potassium oxide $\left(\mathrm{K}_{2} \mathrm{O}\right)$ & 4.80 & 0.58 \\
\hline
\end{tabular}

precipitation (Velmurugan et al. 2015). Silica can be isolated from corn cob by varying $\mathrm{pH}(7-10)$ using the sol-gel method (Shim et al. 2015). The results show a $99.50 \%$ purity, larger surface area, high reactivity and $98.50 \%$ amorphous state. Scanning electron microscopic (SEM) images of corn $\mathrm{cob}$ and silica nanoparticles are displayed in Fig. 9.

Silica nanoparticles from corn cob extracts are also prepared by precipitation. Here, soluble sodium silicate solution from corn cob ash is used as a source of silica, and concentrated sodium hydroxide $(\mathrm{NaOH})$ is used as a source of soda. Various parameters such as specific gravity, $\mathrm{pH}$ value, viscosity and electrical conductivity were studied (Ajayi and
Owoeye 2015). Silica nanoparticles prepared from corn cob yield amorphous silica with large surface area.

\section{Rice husk}

Rice husk has been studied for energy and for production of silica (Liu et al. 2016a, b). For instance, rice husk ash is a precursor for silica gel synthesis by the sol-gel method: here sodium silicate is prepared first then converted into a gel by acid treatment (Geetha et al. 2016). Acid and thermal treatments yield a white color silica with high surface area (Della et al. 2002). Rice husk has about $20 \%$ of minerals (Carmona et al. 2013). Organic compounds include cellulose, hemicellulose and lignin. Minerals contains $94 \%$ of silica and $6 \%$ of $\mathrm{Al}_{2} \mathrm{O}_{3}, \mathrm{~K}_{2} \mathrm{O}, \mathrm{MgO}, \mathrm{CaO}$ and $\mathrm{P}_{2} \mathrm{O}_{5}$. Composition varies depending on soil type, fertilizers and weather conditions (De Souza et al. 2002). The chemical composition of rice husk is shown in Table 5 .

For optimal production of nanosilica from rice husk, the effect of the acid leaching, concentration of sodium silicate solution, reaction temperature and time of aging and gelation, $\mathrm{pH}$ on synthesizing silica nanoparticle, were studied (Liou and Yang 2011). Research also focused on morphology of rich husk ash, which displays a porous structure after washing, acid treatment and sintering (Madrid et al. 2012). As a consequence, rich husk ash shows promising
Fig. 9 Scanning electron microscopy of a corn cob, reprinted with permission from Shariff et al. (2016), b calcined corn cob ash obtained at $650{ }^{\circ} \mathrm{C}$ for $2 \mathrm{~h}, \mathbf{c}$ nanosilica from corn cob, reprinted with permission from Mohanraj et al. (2012), d nano-structured silica from corn cob with an average diameter of $55 \mathrm{~nm}$, reprinted with permission from Okoronkwo et al. (2016)
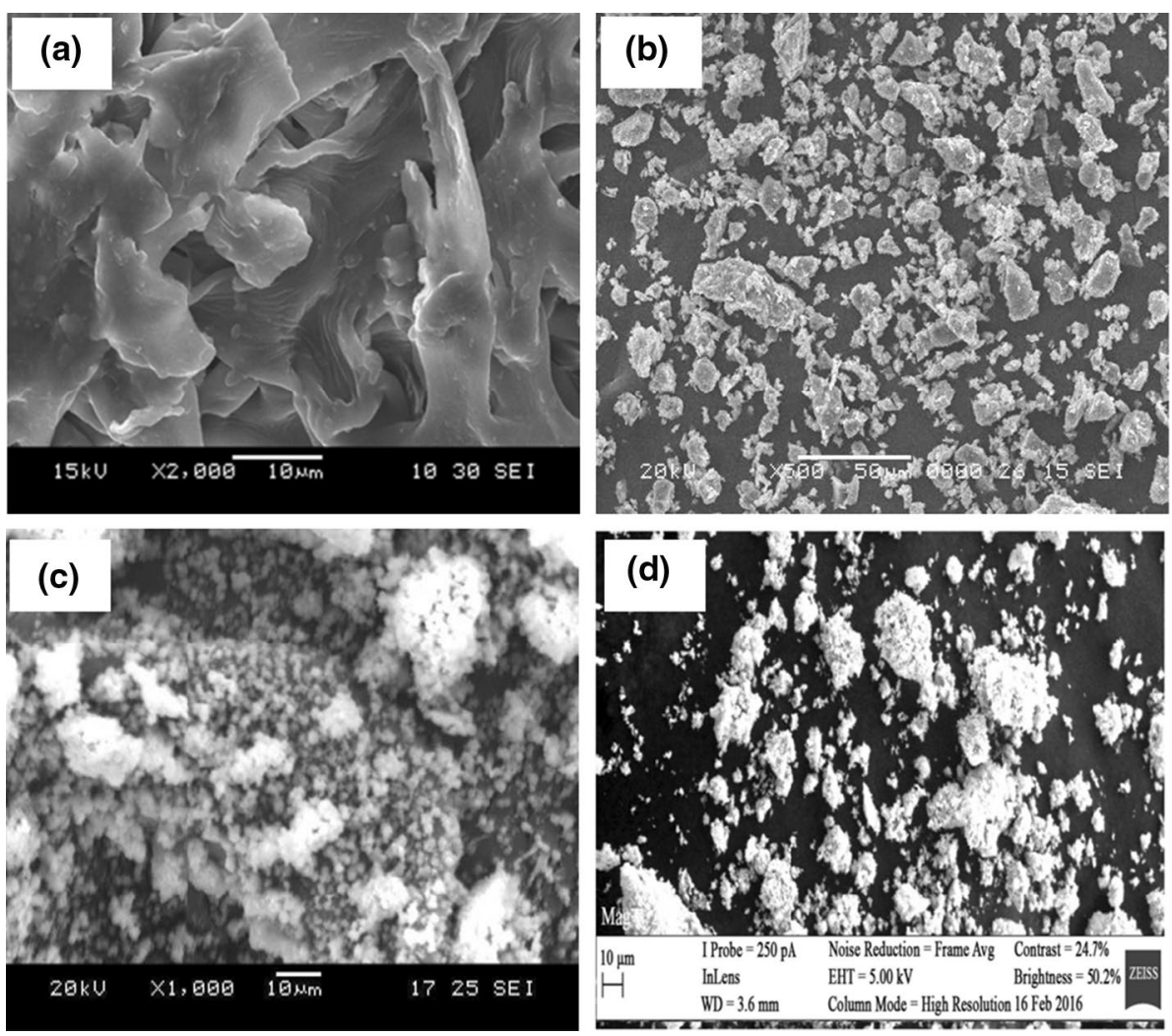
Table 5 Composition of rice husk ash (Ramadhansyah et al. 2012)

\begin{tabular}{ll}
\hline Oxide compounds & Chemical composition (\%) \\
\hline Silicon dioxide $\left(\mathrm{SiO}_{2}\right)$ & 93.0 \\
Aluminum oxide $\left(\mathrm{Al}_{2} \mathrm{O}_{3}\right)$ & 0.20 \\
Iron oxide $\left(\mathrm{Fe}_{2} \mathrm{O}_{3}\right)$ & 0.13 \\
Calcium oxide $(\mathrm{CaO})$ & 0.49 \\
Magnesium oxide $(\mathrm{MgO})$ & 0.73 \\
Sodium oxide $\left(\mathrm{Na}_{2} \mathrm{O}\right)$ & 0.02 \\
Potassium oxide $\left(\mathrm{K}_{2} \mathrm{O}\right)$ & 1.30 \\
Sulfur trioxide $\left(\mathrm{SO}_{3}\right)$ & 0.15 \\
Loss on ignition $(\mathrm{LOI})$ & 3.98 \\
\hline
\end{tabular}

applications for construction materials and technical ceramics due to the high reactivity of the porous structure.

Extraction and characterization of silica from a different rice husks such as agulhinha and cateto were analyzed (Carmona et al. 2013). Highly pure silica nanoparticles with high specific area and an average size of $25 \mathrm{~nm}$ were prepared by alkali extraction, followed by acid precipitation (Yuvakkumar et al. 2014). Research has also focused on 'waste in valuable product manufacture' using silica, revealing good performance and simple industrial implementation as anti-sticking agents, filter in rubber products and paper (Todkar et al. 2016). Silica nanocomposite can be prepared with rice husk ash, which is used as a nanofiller in epoxy-silica nanocomposites; products display good tensile strength, uniform distribution and no agglomeration (Moosa and Saddam 2017). To synthesize high surface area silica aerogel from rice husk ash, the water extract of rice husk is used as a precursor in the sol-gel process (Feng et al. 2018). The image of rice husk, after acid leach of rice husk, and the morphology of rice husk ash and silica nanoparticles are shown in Fig. 10. Overall, rice husk silica can be used to develop valuable products, thus solving the disposal issue (Tyagi et al. 2017).

\section{Sugarcane bagasse}

India has the second largest manufacture of sugarcane in the world. Bagasse is the residue of sugarcane; bagasse is obtained industrially by milling. India produces 10 million tons of sugarcane bagasse ash as a waste material (Goyal et al. 2007). Silica is abundant in sugarcane bagasse ash (Aigbodion et al. 2010; Faria et al. 2012). Mesoporous silica nanoparticles prepared from sugarcane bagasse are applied in biomedical and industrial fields (Rahman et al. 2015). Sugarcane bagasse is considered as a better option
Fig. 10 Scanning electron microscopy. a rice husk. Silica nanoparticles synthesized from rice husk under various conditions giving: b particles in heterogeneous sizes, $\mathbf{c}$ agglomeration, d $50 \mathrm{~nm}$ size (Prabha et al. 2019)
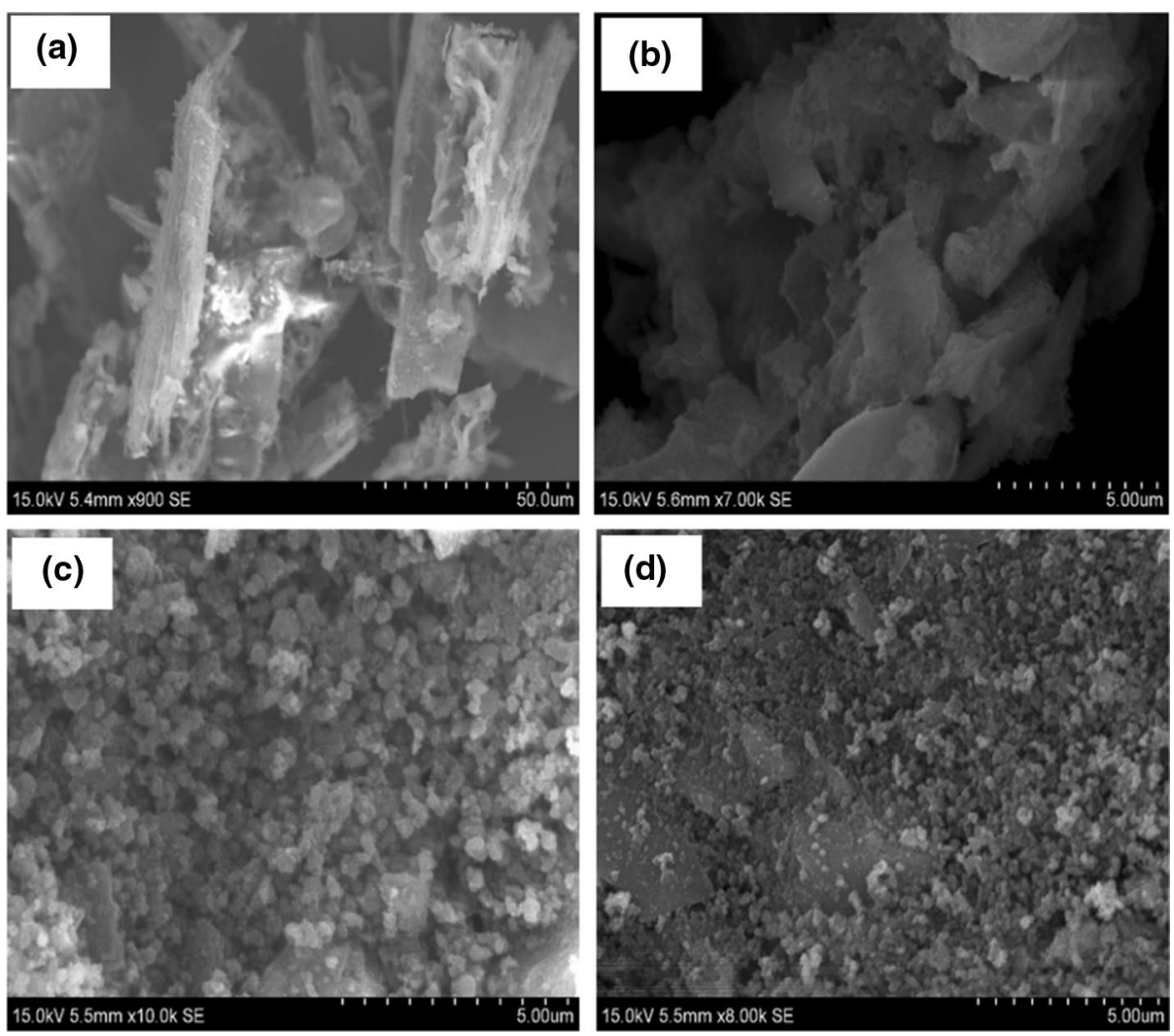
than wood fibers in producing textiles, paper, pressed wood materials and other products (Mandal and Chakrabarty 2011). Silica extracted from sugarcane is suitable as additive for membrane fabrication (Mokhtar et al. 2016). In the nineteenth century, silica was found in plants, and then, silica is generally accepted as a sustainable polymer compound (Hariharan and Sivakumar 2013). The chemical composition of sugarcane bagasse ash is shown in Table 6 (Chusilp et al. 2009).

The effect of calcination temperature and alkali concentration on silica structure have been studied (Rahmat et al. 2016; Athinarayanan et al. 2017). $\mathrm{HCl}$ is used for washing, and $\mathrm{NaOH}$ was for silica extraction. Acid pretreatment in autoclave removes metal ions and induces the hydrolysis

Table 6 Chemical composition of sugarcane bagasse ash (Chusilp et al. 2009)

\begin{tabular}{lc}
\hline Chemical composition $(\%)$ & $\begin{array}{c}\text { Sugarcane } \\
\text { bagasse ash }\end{array}$ \\
\hline Silicon dioxide $\left(\mathrm{SiO}_{2}\right)$ & 64.88 \\
Aluminum oxide $\left(\mathrm{Al}_{2} \mathrm{O}_{3}\right)$ & 6.40 \\
Iron oxide $\left(\mathrm{Fe}_{2} \mathrm{O}_{3}\right)$ & 2.63 \\
Calcium oxide $(\mathrm{CaO})$ & 10.69 \\
$\mathrm{Magnesium} \mathrm{oxide}(\mathrm{MgO})_{\mathrm{SiO}_{2}+\mathrm{Al}_{2} \mathrm{O}_{3}+\mathrm{Fe}_{2} \mathrm{O}_{3}}^{1.55}$ \\
\hline
\end{tabular}

of organic substances. Bagasse ash filler treated with $\mathrm{HCl} /$ $\mathrm{NH}_{4} \mathrm{~F}$ gives silica of $77 \%-97 \%$ purity (Huabcharoen et al. 2017). SEM images of the sugarcane bagasse, bagasse ash and silica nanoparticles from sugarcane bagasse are shown in Fig. 11.

\section{Mesoporous silica}

Porosity is classified according to pore size (Table 7, Barrabino 2011). Porosity is defined as the periodic arrangements with uniform size mesopores integrated within the amorphous silica matrix.

Mesoporous silica material was discovered in 1992 by the Mobil Oil corporation and is known as the M41S phase having pore diameters from about 2 to $10 \mathrm{~nm}$ (Hoffmann et al. 2006). The materials are often referred to as Mobil composition of matter (MCM) (Caras 2011), and the most popular MCM materials are MCM-41 and MCM-48,

Table 7 Classification of porous material (Hoffmann et al. 2006)

\begin{tabular}{ll}
\hline Types of porous material & The diameter of pores $(\mathrm{nm})$ \\
\hline Microporous & Diameter $<2$ \\
Mesoporous & $2<$ diameter $<50$ \\
Macroporous & Diameter $>50$ \\
\hline
\end{tabular}

Fig. 11 Scanning electron microscopy of $15 \%$ sugarcane bagasse at ages of a 7 days and b 28 days, with scale bar of $10 \mathrm{~mm}$. Reprinted with permission from Joshaghani et al. (2017). c Silica-polyethylene glycol (PEG) hybrid. d porous silica after PEG extraction. Reprinted with permission from Rahman et al. (2015)
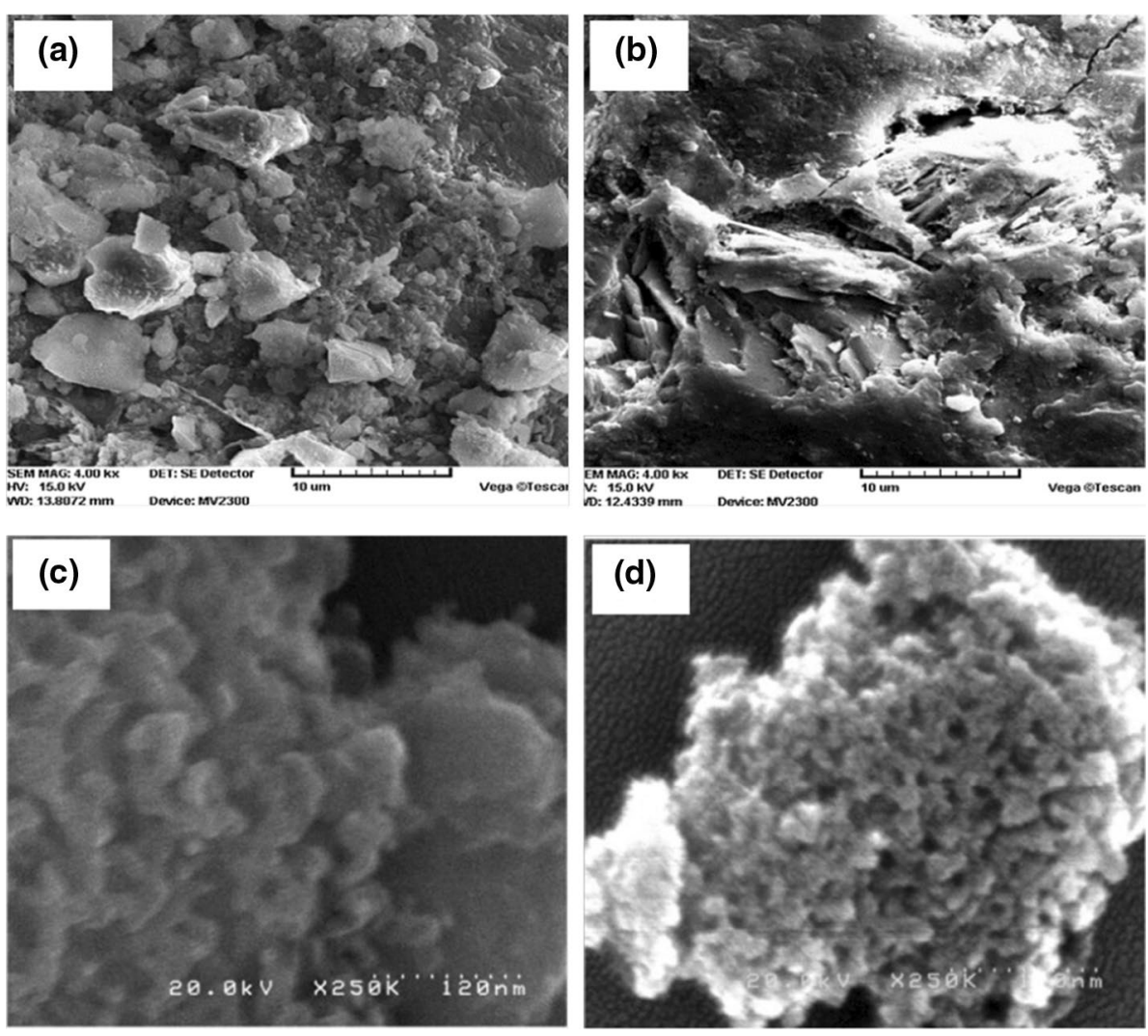
displaying 2D hexagonal and 3D cubic arrangement of pores, respectively (Tzankov et al. 2014). Mesoporous silica got high interest due to tunable particle size $(10-1000 \mathrm{~nm})$ and pore diameter $(2-30 \mathrm{~nm})$, large surface area and pore volume, flexible morphology, surface functionalization and uniform mesoporosity, tunable and narrow pore size distribution, and excellent biocompatibility and biodegradation. Mesoporous silica nanoparticles (MSNPs) have been developed for inorganic delivery (Caras 2011). Mesoporous silica nanoparticles have sizes ranging from 50 to $500 \mathrm{~nm}$ in diameter with pores ranging from 2 to $20 \mathrm{~nm}$; these pores are mainly cylindrical (Kresge et al. 1992). Pores act as vehicles and reservoirs in a wide range of fields such as drug delivery, adsorption and heterogeneous catalysis. Applications include drug delivery of therapeutic agents (Thomas et al. 2010; Slowing et al. 2007; Trewyn et al. 2007).

Microscopic images of mesoporous silica obtained by various methods are shown in Fig. 12. Mesoporous silica nanoparticles are prepared using amphiphilic molecules as templates for their internal structure. Two different structures can be obtained by changing the synthesis conditions, the two-dimensional hexagonal structure known as MCM- 41 (Beck et al. 1992; Kresge et al. 1992) and the tridimensional cubic structure MCM-48 (Hoffmann et al. 2006). Mesoporous silica materials were first synthesized for catalytic applications (Yanagisawa et al. 1990; Kresge et al. 1992). To increase biocompatibility, smaller sizes and homogeneous morphology are required. For instance, submicrometer MCM-41 particles were prepared in 1997 by a modified Stober method (Grün et al. 1997). Later, $100 \mathrm{~nm}$ MCM-41 silica particles were synthesized using a dilute surfactant solution (Cai et al. 2001), and then, less than $50 \mathrm{~nm}$ particles were prepared by dialysis (Suzuki et al. 2004). Overall, mesoporous silica nanoparticles have large pore volume and surface area and can be functionalized with versatile functional groups for theranostic applications.

\section{Core-shell silica}

Core-shell nanoparticles refer as inner material coated with another material on the surface (Law et al. 2008). Core-shell nanoparticles have numerous advantages over conventional nanoparticles in biological applications because these particles display high dispersibility and low cytotoxicity, bio- and cytocompatibility, better conjugation with other bioactive molecules, and increased thermal and chemical stability (Sounderya and Zhang 2008). The core is coated with non-toxic material to make nanoparticles biocompatible. The shell layer reduces the toxic layer and
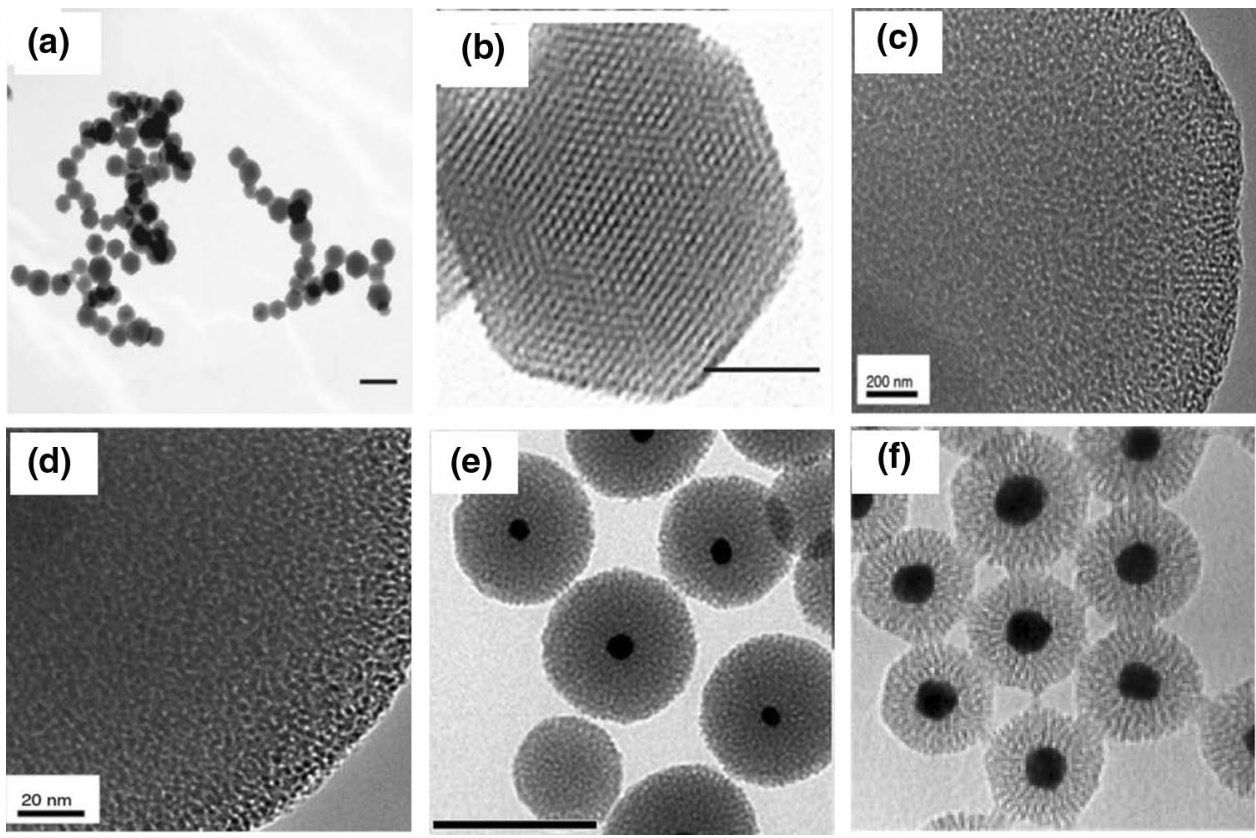

Fig. 12 Transmission electron microscopy (TEM) of a mesoporous silica nanoparticle with an average diameter of $120 \mathrm{~nm}$. b High-resolution image of a single particle, pore size $2.7 \mathrm{~nm}$, reprinted with permission from $\mathrm{Yu}$ et al. (2011). c 0.1 M CTAB:45 $\mathrm{M} \mathrm{H}_{2} \mathrm{O}$ pore size $2.9 \mathrm{~nm}$. d $0.1 \mathrm{M} \mathrm{CTAB}: 45 \mathrm{M} \mathrm{H}_{2} \mathrm{O}$ pore size $2.7 \mathrm{~nm}$, reprinted with permission from Vazquez et al. (2017). e Gold-mesoporous silica under plasmonic photothermal with irradiation for $14 \mathrm{~h}$ at $514 \mathrm{~nm}$ under $15 \mathrm{~mW}$, reprinted with permission from Croissant and Guardado-Alvarez (2019). f Multibranched-polymer composite with goldsilica core-shell nanoparticles, reprinted with permission from Carrasco et al. (2016). CTAB: cetyltrimethylammonium bromide 
enhances the properties of the core material (Chatterjee et al. 2014). Core-shell nanoparticles are mainly designed to increase the binding affinity with ligands, drugs and receptors in biomedical applications (Sahoo and Labhasetwar 2003; Gilmore et al. 2008; Chen et al. 2010). The thickness of the shell can be tuned to improve contrast agents, targeted drug delivery, specific binding and biosensing (Pinho et al. 2010). Microscopic images of silica nanoparticles with a core-shell structure are shown in Fig. 13. Tables 8 and 9 present core-shell silica nanoparticles for biosensor and bioimaging applications.
Fig. 13 Transmission electron microscopy. a Silica-gadolinium particle, reprinted with permission from Kobayashi et al. (2007). b Silver-silica with silica shell thickness of $8 \pm 2 \mathrm{~nm}$ (Song et al. 2016). Core-shell of polystyrene-silica composites (PSC), c silica: styrene 1:10, d silica:styrene 1.5:10, reprinted with permission from Ding et al. (2004). Core-shell of gold-silica at various scales: e $500 \mathrm{~nm}$, f $20 \mathrm{~nm}$. Gold-silica with template of $0.1 \mathrm{~g}$ cetyltrimethylammonium bromide (CTAB) at various scales: $\mathbf{g}$ $200 \mathrm{~nm}, \mathbf{h} 10 \mathrm{~nm}$, reprinted with permission from $\mathrm{Vu}$ et al. (2019). i Core-shell of Au nanostar-silica nanoparticles, reprinted with permission from Al-Ogaidi et al. (2014)
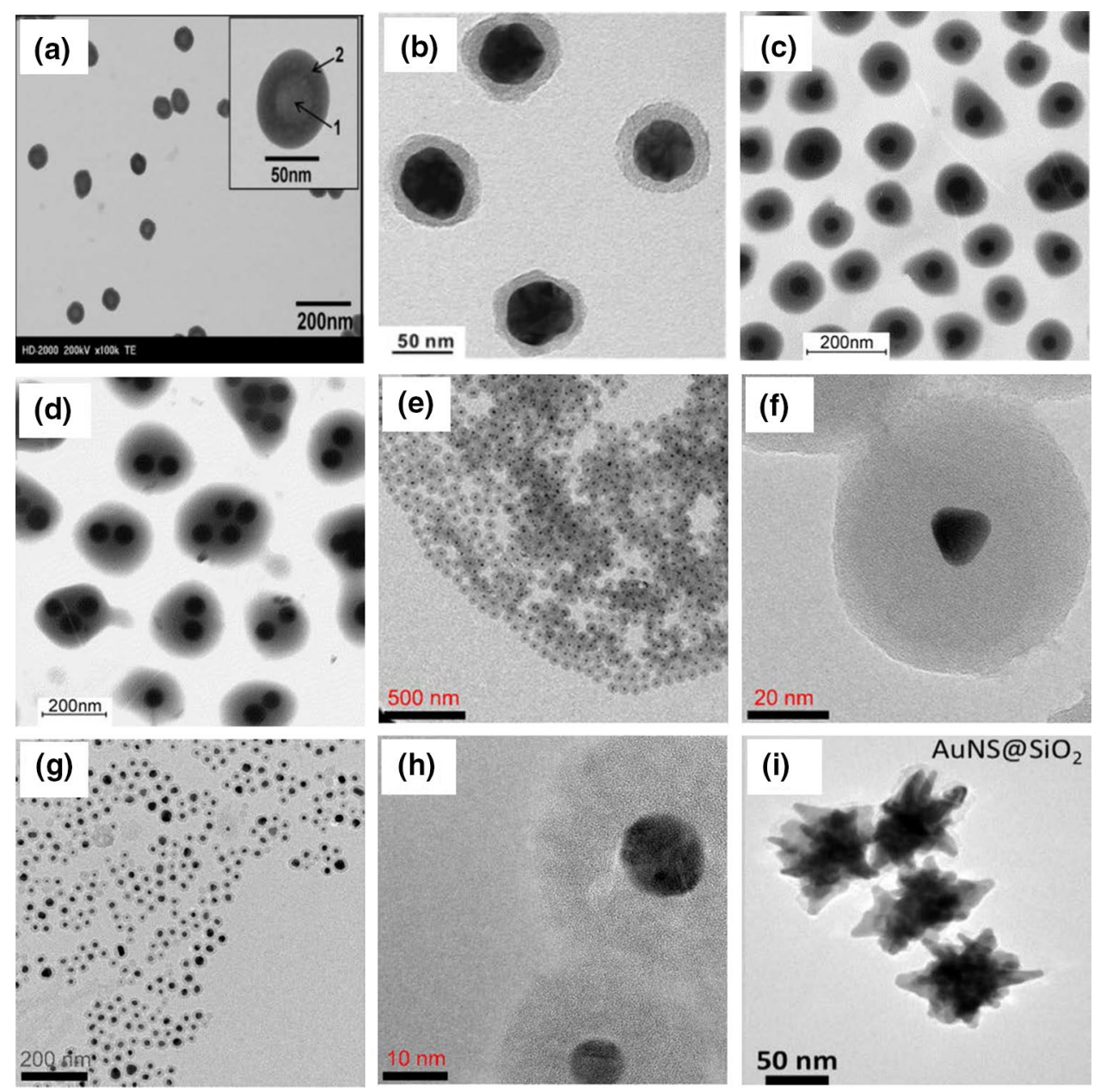
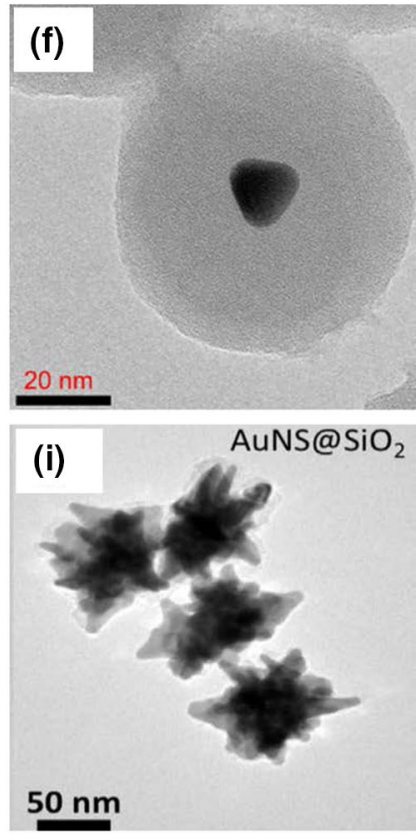

Table 8 Core-shell silica nanoparticles for biosensor applications

\begin{tabular}{|c|c|c|c|}
\hline Core & Shell & Application & References \\
\hline Gold nanostar & Silica nanoparticle & Glucose sensor & Al-Ogaidi et al. (2014) \\
\hline $\begin{array}{l}\text { Teardrop-shaped silica nano- } \\
\text { particles }\end{array}$ & Titanium dioxide nanoparticles & For photocatalytic activity & Wu et al. (2015) \\
\hline Silver nanoparticles & Silica nanoparticles & Aptasensor & Song et al. (2016) \\
\hline DNA-labeled silicon & Silica nanoparticles & $\begin{array}{l}\text { Fluorescent sensor for detection of } \mathrm{Hg}^{2+} \\
\text { in water }\end{array}$ & Srinivasan et al. (2017) \\
\hline $\mathrm{Fe}_{3} \mathrm{O}_{4}$ nanoparticles & $\begin{array}{l}\text { Inner shell: amorphous carbon. Outer } \\
\text { shell: metallic silver nanoparticles }\end{array}$ & Cholesterol nanobiosensors & Satvekar and Pawar (2018) \\
\hline Gold nanoparticles & $\begin{array}{l}\text { Silica nanoparticles and } 4,4^{\prime} \text {-dipyridyl } \\
\text { embedded into the core-shell }\end{array}$ & Detection of E. coli O157: H7 & Zhu et al. (2018) \\
\hline
\end{tabular}


Table 9 Core-shell silica nanoparticles for bioimaging application

\begin{tabular}{|c|c|c|c|}
\hline Core & Shell & Application & References \\
\hline Gadolinium & Silica nanoparticle & $\mathrm{X}$-ray imaging & Morimoto et al. (2011) \\
\hline Iron oxide & Silica with different thicknesses & $\begin{array}{l}\text { Multimodal molecular imaging: MRI and optical } \\
\text { imaging }\end{array}$ & Jang et al. (2014) \\
\hline Gadolinium & Mesoporous silica & Drug delivery & Stefanakis and Ghanotakis (2014) \\
\hline Quantum dot & Silica nanoparticle & $\begin{array}{l}\text { Contrast agent with dual functions fluorescence and } \\
\text { X-ray absorption }\end{array}$ & Kobayashi et al. (2016) \\
\hline $\begin{array}{l}\text { Monodisperse } \\
\text { silica nanopar- } \\
\text { ticle }\end{array}$ & $\begin{array}{l}\text { amorphous gadolinium and euro- } \\
\text { pium oxides with mesoporous } \\
\text { silica }\end{array}$ & $\begin{array}{l}\text { Drug delivery, fluorescence and magnetic resonance } \\
\text { imaging }\end{array}$ & Eurov et al. (2015) \\
\hline
\end{tabular}

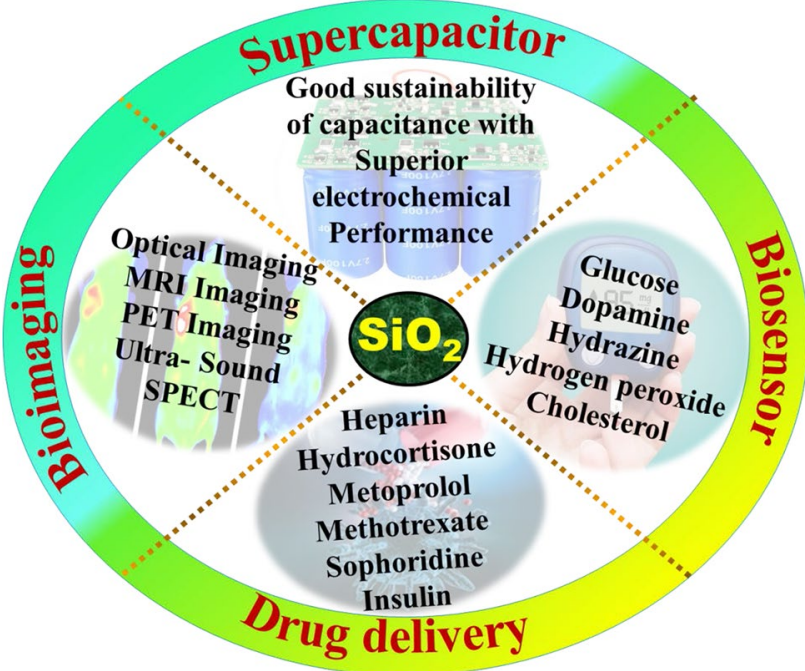

Fig. 14 Applications of silica nanoparticles

\section{Applications of silica nanoparticles}

Silica nanoparticles are used in many fields such as biomedical, electrical, textile and rubber sectors, yet nowadays research is moving toward the biomedical field. Here silica nanoparticles are used in diagnosis and to control diseases by identifying and correcting the genetic disorders, as a theranostics agent. In addition, some applications such as biosensor, bioimaging, drug delivery and supercapacitor are briefly discussed. Applications of silica nanoparticles are shown in Fig. 14 and Table 10.

\section{Biosensors}

Sensors are the analytical device that consists of an active sensing material with a signal transducer (Kuswandi 2019). In general, sensors can be categorized into two types: biosensors and chemical sensors. This classification is based on sensing aspects, where the biosensors can sense biochemical compounds such as enzymes (Verma 2017), antibodies, nucleic acids, cells and tissues (Yogeswaran and Chen 2008). Biosensors typically consist of two intimately associated elements: a bioreceptor and a transducer. Based on the transducing mechanism, biosensors are further classified as (i) optical-detection biosensors, (ii) resonant biosensors, (iii) thermal detection biosensors, (iv) ion-sensitive field-effect transistor-based biosensors and (v) electrochemical biosensors (Chaubey and Malhotra 2002). Numerous electrochemical biosensors have been developed for determining various substances such as glucose (Saei et al. 2013), cholesterol (Hui et al. 2015), dopamine (Huang et al. 2015), hydrazine (Liu et al. 2016a, b), hydrogen peroxide (Ju and Chen 2015), kanamycin (Qin et al. 2016) and cysteine (Amiri et al. 2017). Optical biosensors are applicable in environmental monitoring, biomedical research, pharmaceuticals, healthcare, homeland security and the battlefield due to powerful detection and analysis tools (Amiri et al. 2017).

For non-enzymatic detection of hydrogen peroxide $\left(\mathrm{H}_{2} \mathrm{O}_{2}\right)$, graphene oxide was composited with silica nanoparticles (Huang and Li 2013). Amperometric studies show that composites of graphene oxide and silica nanoparticles enhance the electrochemical activity of hydrogen peroxide detection in alkaline medium, with a low detection limit of $2.6 \mu \mathrm{M}$ and high reproducibility. Functionalized mesoporous silica is used for detection of $\mathrm{H}_{2} \mathrm{O}_{2}$ and controlled treatment of heart failure (Tan et al. 2017). Here, the $\mathrm{H}_{2} \mathrm{O}_{2}$-sensitive probe is attached to the surface of a mesoporous silica nanoparticles (MSNP), and captopril, a drug for heart failure, is loaded inside the pores of nanoparticles. A MSNP-based system of high loading efficiency and releasing capacity was developed and combined with detection by chemiluminescence of luminol / hydrogen peroxide (Chen et al. 2016). For dengue RNA detection, 3-aminopropyltriethoxysilane (APTES)-functionalized graphene oxide was enclosed in silica nanoparticles (Jin et al. 
Table 10 Applications of silica nanoparticles

\begin{tabular}{|c|c|c|}
\hline Material & Application & Process \\
\hline Gold nanoparticles-mesoporous silica composite & Glucose Biosensor & $\begin{array}{l}\text { Combining gold nanoparticles-mesoporous silica. Biosensor made by } \\
\text { immobilizing } \mathrm{IO}_{4}^{-} \text {-oxidized-glucose oxidase on gold nanoparticles- } \\
\text { mesoporous silica. Modified gold electrode with } 2 \text {-aminoethanethiol } \\
\text { as a cross-linker (Bai et al. 2007) }\end{array}$ \\
\hline Hollow silica spheres & DNA Biosensor & $\begin{array}{l}\text { Depositing gold nanoparticle/hollow silica spheres on a screen-printed } \\
\text { carbon paste electrode for the detection of E.coli DNA. Using } \\
\text { glutaraldehyde bifunctional cross-linker, an aminated DNA probe is } \\
\text { coupled to the aminated hollow silica spheres and deposited onto the } \\
\text { electrode of gold nanoparticle-modified screen-printed carbon paste } \\
\text { (Ariffin et al. 2018) }\end{array}$ \\
\hline $\begin{array}{l}\text { TAT (cell penetrating peptide) conjugated with } \\
\text { fluorescein isothiocyanate and doped silica } \\
\text { nanoparticles }\end{array}$ & Bioimaging & $\begin{array}{l}\text { Human lung adenocarcinoma (A549) cells (in vitro) and rat brain } \\
\text { tissue (in vivo) tagged with nanoparticles. Endovascular approach } \\
\text { targets brain blood vessels to study blood-brain barrier (Santra et al. } \\
\text { 2004) }\end{array}$ \\
\hline $\begin{array}{l}\text { Carbon dots inserted in a silica shell around } \\
\text { polylactide-polyethylene-glycol conjugated silica } \\
\text { core }\end{array}$ & Bioimaging & $\begin{array}{l}\text { Fluorescence induced by incorporation of carbon dots into silica } \\
\text { nanoparticle shell. Carbon dots with silane groups on the silica shell } \\
\text { using a one-pot reaction. For cellular uptake, silica-loaded core are } \\
\text { incubated with A549 cells line and studied for drug release and } \\
\text { bioimaging Silica core-shell material proved promising materials for } \\
\text { both bioimaging and anticancer drug delivery (Mehdi et al. 2018) }\end{array}$ \\
\hline Mesoporous MCM-41 silica & Drug delivery & $\begin{array}{l}\text { Mesoporous MCM- } 41 \text { is loaded with ibuprofen. Drug release in a } \\
\text { simulated body fluid. Drug release analyzed in amine-functionalized } \\
\text { MCM- } 41 \text { of micro-sized sphere and irregular shape. Non-function- } \\
\text { alized mesoporous silica shows lower drug release. For amine-func- } \\
\text { tionalized mesoporous silica, drug release rate is better for spherical } \\
\text { shape compared to irregular shape (Manzano et al. 2008) }\end{array}$ \\
\hline Mesoporous silica nanoparticles & Drug delivery & $\begin{array}{l}\text { Interactions with fluorescent unilamellar vesicles and dye-loaded } \\
\text { mesoporous silica nanoparticles. Time-resolved fluorescence and } \\
\text { steady-state techniques to study live cells fluorescence imaging } \\
\text { Release of dye molecules from the pores of mesoporous silica nano- } \\
\text { particles is observed (Bardhan et al. 2018) }\end{array}$ \\
\hline Hollow-core mesoporous shell carbon nanospheres & Supercapacitor & $\begin{array}{l}\text { Uniform hollow-core mesoporous shell carbon nanospheres fabri- } \\
\text { cated by a surface co-assembly of monodisperse silica nanospheres } \\
\text { method. This strategy is easier compared to other methods. } 2.0 \mathrm{M} \\
\text { sulfuric acid solution as the electrolyte: working electrode is hollow- } \\
\text { core mesoporous shell carbon nanospheres coated glass carbon } \\
\text { electrode, platinum electrode used as a counter. Good sustainability } \\
\text { of capacitance (You et al. 2011) }\end{array}$ \\
\hline
\end{tabular}

2016). Results showed better selectivity and lower detection limit than graphene oxide without enclosed silica.

\section{Bioimaging}

Silica nanoparticles can be easily utilized for molecular imaging techniques, such as optical imaging, e.g., fluorescence and bioluminescence, magnetic resonance imaging (MRI), radionuclide imaging, e.g., positron emission tomography (PET) and single-photon emission computed tomography (SPECT), computed tomography (CT), ultrasound, photoacoustic imaging and Raman imaging (Tang and Cheng 2013). Silica nanoparticles are used as contrast agents in medical imaging to encapsulate contrast agent particles such as an iron oxide (Lee et al. 2009), gold (Viarbitskaya et al.
2011), silver (Gong et al. 2007), organic dyes (Yuan et al. 2005) and quantum dots (Hagura et al. 2011).

The 20-30 nm silica-coated fluorophore is photostable, and brightness is 20 times higher than composing fluorophores (Ow et al. 2005). The outer silica shell allows target specific cells and tissues by silica surface functionalization (Ow et al. 2005). Computed tomography is mostly used in diagnosis due to the limited depth of tissue penetration (Liu et al. 2012). A hybrid of silica with gold nanoparticles and fluorescein isothiocyanate dyes display a strong fluorescence signal at $520 \mathrm{~nm}$ under $490 \mathrm{~nm}$ excitation (Feng et al. 2014).

Silica-coated gold nanospheres can be coated with fluorescent quantum dots, yet further coating with silica is needed to reduce the defects of quantum dots (Song et al. 2015). This composite was used for contrast-enhanced computed tomography and fluorescence imaging. The probe of 
in vivo gastric cancer cells using folic acid-conjugated silica coated with gold nanoclusters of about $58 \mathrm{~nm}$ size was used for computed tomography and fluorescence imaging (Zhou et al. 2013). Magnetic resonance imaging is mostly used for noninvasive diagnostic techniques (Viswanathan et al. 2010). Silica-coated gadolinium nanoparticles co-doped with europium $\left(\mathrm{Eu}^{3+}\right)$ and terbium $\left(\mathrm{Tb}^{3+}\right)$ were used for magnetic resonance and fluorescence imaging. Gadolinium carbonate particles are often used in magnetic resonance imaging. To increase biocompatibility, biomass-derived silica nanoparticles were conjugated with a fluorescent material and used for biological imaging application (Pandey et al. 2014). Here, meso-silica nanoparticles derived from rice husk were composited with green fluorescent carbon dots by hot injection. The complex shows high drug loading efficiency and stronger fluorescence compared to carbon dots alone. Thus, this complex material can be used for theranostic applications. Rice husk-derived silica composite with rare earth elements, europium/gadolinium ions were prepared by microwave-assisted combustion (Araichimani et al. 2020). Europium ions and gadolinium ions in the silica matrix exhibited potential of fluorescence imaging and T1-weighted magnetic resonance imaging, respectively. Thus, rice husk silica nanoparticles with rare earth ions are a good alternative for developing cost-effective bioimaging contrast agents.

\section{Drug delivery}

Drug delivery systems based on silica nanoparticles are fastdeveloping in nanomedicine, yet it requires the analysis of toxicity, biodistribution, clearance and immune response of silica and modified silica (Biju 2014). Mesoporous silica nanoparticles are widely used for drug delivery application (Chowdhury 2018). Owing to the presence of surface silanol groups, they can be functionalized to tune the load and release of drugs (Vallet-Regí et al. 2007). Amine-functionalized mesoporous silica nanoparticles are widely used (Vallet-Regí et al. 2011). High drug loading and slow drug release are observed (Chowdhury, 2016). A such approach has been used for various drugs, e.g., heparin (Wan et al. 2012), hydrocortisone (Lopez et al. 2009), metoprolol (Guo et al. 2010), salidroside (Peng et al. 2013), venlafaxine (Tang et al. 2011), vancomycin (Lai et al. 2003), methotrexate (Carino et al. 2007), sophoridine (Dong et al. 2014) insulin and cyclic adenosine monophosphate (cAMP, Zhao et al. 2010), and anticancer drugs such as doxorubicin and 5-fluorouracil (Singh et al. 2011b; Mei et al. 2012; Wu et al. 2013a, b; Hwang et al. 2015).

Magnetic carbon nanotubes composited with mesoporous silica shows a high loading capacity for therapeutic molecules such as protein cytochrome $\mathrm{C}$ and drug gentamicin (Singh et al. 2014b). Small interfering RNA (siRNA) was loaded and then released over a days to a week. Transferrin was grafted on the surfaces of mesoporous silica nanoparticles by a redox-cleavable disulfide bond, then was used as capping agent and targeting ligand (Chen et al. 2017). To examine the redox-responsive and burst release of doxorubicin, transferrin was integrated into mesoporous silica nanoparticles with the presence and absence of glutathione. Here, the presence of glutathione has perfect capping efficiency of transferrin and also enhanced the biocompatibility.

Nanocarriers of amine-modified mesoporous silica-iron oxide functionalized with 2, 3-dimercaptosuccinic acid via chemical amidation show that a negligible amount of the drug is released in the absence of a magnetic field (Chen et al. 2011). Upon application of a magnetic field, nanocaps are removed by chemical bond breaking, which induces high drug release. This material is also applicable for molecular imaging by $\mathrm{T}_{2}$-weighted magnetic resonance contrast influencing agents. Composites of rice husk-derived silica nanoparticles and polycaprolactone nanofibers are used for drug delivery of drugs such as allantoin (Ke et al. 2016). To reduce cost and increase biocompatibility, 5-fluorouracil was fixed to chitosan-coated biomass silica nanoparticles (Dhinasekaran et al. 2020). The results showed that potential in targeting the cancer cell lines MCF-7 and A549.

\section{Supercapacitors}

Supercapacitors have attracted interest owing to their extended cycle life performance, high charge/discharge rates and high power density (Miller and Simon 2008; Liu et al. 2010; Simon and Gogotsi 2010). Supercapacitors are considered as a very promising energy storage device to complement or eventually replace the batteries of wearable and portable electronics, and electrical and hybrid vehicles (Kaempgen et al. 2009). Supercapacitors can be classified into two main categories according to the energy storage mechanisms: electric double-layer capacitors (EDLC) and pseudocapacitors (Winter and Brodd 2004). Mesoporous silica nanoparticles with conducting polyaniline wires wrapped with graphene oxide were found to expand the surface area and allow the movement of ions and charge transfer (Javed et al. 2018)

Manganese dioxide/mesoporous nanocomposite are obtained by facile chemical synthesis and then used as electrode material for supercapacitor applications, thus displayed superior electrochemical performance (Huang et al. 2017). Rice-derived silicon was composited with carbon $\left(\mathrm{SiO}_{x} / \mathrm{C}\right)$ for Li-ion batteries by one-step pyrolysis exhibiting $\mathrm{SiO}_{\mathrm{x}} / \mathrm{C}$ anode specific capacity of $654 \mathrm{mAh} \mathrm{g}^{-1}$ after 1000 cycles, with higher capacity up to $920 \mathrm{mAh} \mathrm{g}^{-1}$ (Huang et al. 2019). To use rice husk for energy storage, tin oxide was decorated on huskderived silica nanoparticles by facile microwave combustion 
(Vijayan et al. 2020). Here, the presence tin oxide on silica nanosphere provides reactive surfaces for charges adsorption and desorption.

Silica nanoparticles are not only used in the biomedical field but also used in various fields such as material packing, textile (Riaz et al. 2019), agriculture and food (Rastogi et al. 2019), adsorbents in the removal of organic and inorganic pollutants (Morin-Crini et al. 2019), rubber field (Peng et al. 2007), water treatment (Demadis and Mavredaki 2005), concrete and construction and photocatalytic degradation (Alaoui et al. 2009 and Batista et al. 2010).

\section{Conclusion}

Silica nanoparticles are promising material for medical and electronics applications. Because of its optoelectronic properties, silicon $(\mathrm{Si})$ is extensively used in photovoltaic and energy storage applications. Recently, the application of silica is also explored in biomedical fields in the form of silica nanoparticles as bioimaging, biosensors and drug delivery, due to its biocompatibility, biodegradability and low toxicity. The silica nanoparticles can be prepared by different methods and most of the researchers used the well-known Stober method to get monodispersed particles with narrow size distribution. Compared to silica nanoparticles prepared using tetraethylorthosilicate as a precursor, silica nanoparticles from biomass are exhibiting good properties at low cost. Silica sources can also be obtainable from rice husk, sugarcane bagasse, corn cob and wheat husk.

Acknowledgement D. Durgalakshmi gratefully acknowledges the Department of Science \& Technology (DST) Innovation in Science Pursuit for Inspired Research (INSPIRE) under Faculty scheme (DST/ INSPIRE/04/2016/000845), New Delhi.

\section{References}

Adesanya D, Raheem A (2009) Development of corn cob ash blended cement. Constr Build Mater 23(1):347-352. https://doi. org/10.1016/j.conbuildmat.2007.11.013

Aigbodion V, Hassan S, Ause T, Nyior G (2010) Potential utilization of solid waste (bagasse ash). J Minerals Mater Characterization Eng 9(01):67. https://doi.org/10.4236/jmmce.2010.91006

Ajayi B, Owoeye S (2015) Extraction of soluble sodium silicate using corn cob ash as a silica source. Am J Eng Res 4(9):54-56

Alaoui OT, Nguyen QT, Rhlalou TJECL (2009) Preparation and characterization of a new $\mathrm{TiO} 2 / \mathrm{SiO} 2$.composite catalyst for photocatalytic degradation of indigo carmin. Environ Chem Lett 7(2):175-181. https://doi.org/10.1007/s10311-008-0154-1

Al-Ogaidi I, Gou H, Al-Kazaz AKA, Aguilar ZP, Melconian AK, Zheng P, Wu N (2014) A gold@ silica core-shell nanoparticlebased surface-enhanced Raman scattering biosensor for labelfree glucose detection. Anal Chim Acta 811:76-80. https://doi. org/10.1016/j.aca.2013.12.009

Amiri M, Salavati-Niasari M, Akbari A (2017) A magnetic CoFe $2 \mathrm{O} 4 / \mathrm{SiO} 2$ nanocomposite fabricated by the sol-gel method for electrocatalytic oxidation and determination of L-cysteine. Microchim Acta 184(3):825-833. https://doi.org/10.1007/s0060 4-016-2064-4

Araichimani P, Prabu K, Kumar GS, Karunakaran G, Van Minh N, Karthi S, Girija E, Kolesnikov E (2020) Rare-earth ions integrated silica nanoparticles derived from rice husk via microwave-assisted combustion method for bioimaging applications. Ceram Int 46(11):18366-18372. https://doi.org/10.1016/j.ceram int.2020.04.125

Aribo S (2011) Effect of varying corn cob and rice husk ashes on properties of moulding sand. J Minerals Mater Characterization Eng 10(15):1449. https://doi.org/10.4236/jmmce.2011.1015112

Ariffin EY, Lee YH, Futra D, Tan LL, Karim NHA, Ibrahim NNN, Ahmad A (2018) An ultrasensitive hollow-silica-based biosensor for pathogenic Escherichia coli DNA detection. Anal Bioanal Chem 410(9):2363-2375. https://doi.org/10.1007/s0021 6-018-0893-1

Atabaev TS, Lee JH, Han D-W, Choo KS, Jeon UB, Hwang JY, Yeom JA, Kang C, Kim H-K, Hwang Y-H (2016) Multicolor nanoprobes based on silica-coated gadolinium oxide nanoparticles with highly reduced toxicity. RSC Adv 6(24):19758-19762. https ://doi.org/10.1039/c5ra27685c

Athinarayanan J, Periasamy VS, Alhazmi M, Alshatwi AA (2017) Synthesis and biocompatibility assessment of sugarcane bagassederived biogenic silica nanoparticles for biomedical applications. J Biomed Mater Res B Appl Biomater 105(2):340-349. https:// doi.org/10.1002/jbm.b.33511

Azlina H, Hasnidawani J, Norita H, Surip S (2016) Synthesis of $\mathrm{SiO} 2$ nanostructures using sol-gel method. Acta Phys Pol A 129(4):842-844. https://doi.org/10.12693/aphyspola.129.842

Azmi M, Ismail N, Rizamarhaiza M, Taib H (2016) Characterisation of silica derived from rice husk (Muar, Johor, Malaysia) decomposition at different temperatures, AIP Conference Proceedings. AIP Publishing, College Park. https://doi.org/10.1063/1.4958748

Babaso PN, Sharanagouda H (2017) Rice husk and its applications. Int J Curr Microbiol Appl Sci 6(10):1144-1156. https://doi. org/10.20546/ijcmas.2017.610.138

Bae SW, Tan W, Hong J-I (2012) Fluorescent dye-doped silica nanoparticles: new tools for bioapplications. Chem Commun 48(17):2270-2282. https://doi.org/10.1039/c2cc16306c

Bai Y, Yang H, Yang W, Li Y, Sun C (2007) Gold nanoparticlesmesoporous silica composite used as an enzyme immobilization matrix for amperometric glucose biosensor construction. Sensors Actuators B Chem 124(1):179-186. https://doi.org/10.1016/j. snb.2006.12.020

Balagna C, Perero S, Percivalle E, Nepita EV, Ferraris M (2020) Virucidal effect against coronavirus SARS-CoV-2 of a silver nanocluster/silica composite sputtered coating. Open Ceram 1:100006. https://doi.org/10.1016/j.oceram.2020.100006.

Bardhan M, Majumdar A, Jana S, Ghosh T, Pal U, Swarnakar S, Senapati D (2018) Mesoporous silica for drug delivery: Interactions with model fluorescent lipid vesicles and live cells. J Photochem Photobiol B 178:19-26. https://doi.org/10.1016/j.jphotobiol .2017.10.023

Barrabino A (2011) Synthesis of mesoporous silica particles with control of both pore diameter and particle size. Master's thesis

Batista AP, Carvalho HWP, Luz GH, Martins PF, Gonçalves M, Oliveira LCJECL (2010) Preparation of $\mathrm{CuO} / \mathrm{SiO} 2$ and photocatalytic activity by degradation of methylene blue. Environ Chem Lett 8(1):63-67. https://doi.org/10.1007/s10311-008-0192-8

Beck JS, Vartuli J, Roth WJ, Leonowicz M, Kresge C, Schmitt K, Chu C, Olson DH, Sheppard E, McCullen S (1992) A new family of mesoporous molecular sieves prepared with liquid crystal templates. J Am Chem Soc 114(27):10834-10843. https://doi. org/10.1021/ja00053a020 
Beganskienė A, Sirutkaitis V, Kurtinaitienė M, Juškėnas R, Kareiva A (2004) FTIR, TEM and NMR investigations of Stöber silica nanoparticles. Mater Sci (Medžiagotyra) 10:287-290

Bell R, Bird N, Dean P (1968) The vibrational spectra of vitreous silica, germania and beryllium fluoride. J Phys C Solid State Phys 1(2):299. https://doi.org/10.1088/0022-3719/1/2/304

Bharti C, Nagaich U, Pal AK, Gulati N (2015) Mesoporous silica nanoparticles in target drug delivery system: a review. Int J Pharmaceutical Investigation 5(3):124. https://doi.org/10.4103/2230$973 x .160844$

Biju V (2014) Chemical modifications and bioconjugate reactions of nanomaterials for sensing, imaging, drug delivery and therapy. Chem Soc Rev 43(3):744-764. https://doi.org/10.1039/c3cs6 $0273 \mathrm{~g}$

Bhuvaneshwari S, Hettiarachchi H, Meegoda JN (2019) Crop residue burning in India: policy challenges and potential solutions. Int J Environ Res Public Health 16(5):832. https://doi.org/10.3390/ ijerph16050832

Bleta R, Ponchel A, Monflier E (2018) Cyclodextrin-based supramolecular assemblies: a versatile toolbox for the preparation of functional porous materials. Environ Chem Lett 16:1393-1413. https://doi.org/10.1007/s10311-018-0768-x

Bogush G, Tracy M, Zukoski Iv C (1988) Preparation of monodisperse silica particles: control of size and mass fraction. J NonCryst Solids 104(1):95-106. https://doi.org/10.1016/00223093(88)90187-1

Bosio A, Rodella N, Gianoncelli A, Zacco A, Borgese L, Depero L, Bingham P, Bontempi EJEcl (2013) A new method to inertize incinerator toxic fly ash with silica from rice husk ash. Environ Chem Lett 11(4):329-333. https://doi.org/10.1007/s1031 1-013-0411-9

Brinker CJ, Scherer GW (2013) Sol-gel science: the physics and chemistry of sol-gel processing. Academic Press, New York

Burda C, Chen X, Narayanan R, El-Sayed MA (2005) Chemistry and properties of nanocrystals of different shapes. Chem Rev 105(4):1025-1102. https://doi.org/10.1021/cr030063a

Cai Q, Luo Z-S, Pang W-Q, Fan Y-W, Chen X-H, Cui F-Z (2001) Dilute solution routes to various controllable morphologies of MCM-41 silica with a basic medium. Chem Mater 13(2):258263. https://doi.org/10.1021/cm990661z

Caras A (2011) Glucan particle delivery of mesoporous silicadrug nanoparticles. UMASS Medical School. https://doi. org/10.1155/2012/143524

Carino IS, Pasqua L, Testa F, Aiello R, Puoci F, Iemma F, Picci N (2007) Silica-based mesoporous materials as drug delivery system for methotrexate release. Drug Delivery 14(8):491-495. https://doi.org/10.1080/10717540701606244

Carmona V, Oliveira R, Silva W, Mattoso L, Marconcini J (2013) Nanosilica from rice husk: extraction and characterization. Ind Crops Prod 43:291-296. https://doi.org/10.1016/j.inder op.2012.06.050

Carrasco S, Benito-Peña E, Navarro-Villoslada F, Langer J, SanzOrtiz MN, Reguera J, Moreno-Bondi L-M, MCJCoM, (2016) Multibranched gold-mesoporous silica nanoparticles coated with a molecularly imprinted polymer for label-free antibiotic surface-enhanced Raman scattering analysis. Chem Mater 28(21):7947-7954. https://doi.org/10.1021/acs.chemm ater.6b03613

Chandrasekhar S, Satyanarayana K, Pramada P, Raghavan P, Gupta $\mathrm{T}$ (2003) Review processing, properties and applications of reactive silica from rice husk-an overview. J Mater Sci 38(15):3159-3168. https://doi.org/10.1023/a:1025157114800

Chatterjee K, Sarkar S, Rao KJ, Paria S (2014) Core/shell nanoparticles in biomedical applications. Adv Coll Interface Sci 209:8-39. https://doi.org/10.1016/j.cis.2013.12.008
Chaubey A, Malhotra B (2002) Mediated biosensors. Biosens Bioelectron 17(6-7):441-456

Chen M, Xia L, Xue P (2007) Enzymatic hydrolysis of corncob and ethanol production from cellulosic hydrolysate. Int Biodeterior Biodegradation 59(2):85-89. https://doi.org/10.1016/j. ibiod.2006.07.011

Chen P-J, Hu S-H, Hsiao C-S, Chen Y-Y, Liu D-M, Chen S-Y (2011) Multifunctional magnetically removable nanogated lids of $\mathrm{Fe}$ 3 O 4-capped mesoporous silica nanoparticles for intracellular controlled release and MR imaging. J Mater Chem 21(8):25352543. https://doi.org/10.1039/c0jm02590a

Chen S, Wang L, Duce SL, Brown S, Lee S, Melzer A, Cuschieri SA, André P (2010) Engineered biocompatible nanoparticles for in vivo imaging applications. J Am Chem Soc 132(42):1502215029. https://doi.org/10.1021/ja106543j

Chen X, Sun H, Hu J, Han X, Liu H, Hu Y (2017) Transferrin gated mesoporous silica nanoparticles for redox-responsive and targeted drug delivery. Colloids Surf B 152:77-84. https://doi. org/10.1016/j.colsurfb.2017.01.010

Chen Z, Tan Y, Xu K, Zhang L, Qiu B, Guo L, Lin Z, Chen G (2016) Stimulus-response mesoporous silica nanoparticlebased chemiluminescence biosensor for cocaine determination. Biosens Bioelectron 75:8-14. https://doi.org/10.1016/j. bios.2015.08.006

Chowdhury MA (2016) The controlled release of drugs and bioactive compounds from mesoporous silica nanoparticles. Curr Drug Deliv 13(6):839-856. https://doi.org/10.2174/156720181366615 1202195104

Chowdhury MA (2018) Silica materials for biomedical applications in drug delivery, bone treatmentor regeneration, and MRI contrast agent. Rev J Chem 8(2):223-241. https://doi.org/10.1134/s2079 978018020024

Chusilp N, Jaturapitakkul C, Kiattikomol K (2009) Effects of LOI of ground bagasse ash on the compressive strength and sulfate resistance of mortars. Constr Build Mater 23(12):3523-3531. https://doi.org/10.1016/j.conbuildmat.2009.06.046

Corr SA, Rakovich YP, Gun'ko YK (2008) Multifunctional magnetic-fluorescent nanocomposites for biomedical applications. Nanoscale Res Lett 3(3):87. https://doi.org/10.1007/s1167 1-008-9122-8

Croissant JG, Guardado-Alvarez TMJI (2019) Photocracking silica: tuning the plasmonic photothermal degradation of mesoporous silica encapsulating gold nanoparticles for Cargo release. Inorganics 7(6):72. https://doi.org/10.3390/inorganics7060072

Dabbaghian M, Babalou A, Hadi P, Jannatdoust E (2010) A parametric study of the synthesis of silica nanoparticles via sol-gel precipitation method. Int J Nanosci Nanotechnol 6(2):104-113

De Souza M, Magalhães W, Persegil M (2002) Silica derived from burned rice hulls. Mater Res 5(4):467-474. https://doi. org/10.1590/s1516-14392002000400012

Della VP, Kühn I, Hotza D (2002) Rice husk ash as an alternate source for active silica production. Mater Lett 57(4):818-821. https:// doi.org/10.1016/s0167-577x(02)00879-0

Demadis KD, Mavredaki EJECL (2005) Green additives to enhance silica dissolution during water treatment. Environ Chem Lett 3(3):127-131. https://doi.org/10.1007/s10311-005-0015-0

Devi MG, Balachandran S (2016) A review on synthesis, characterization and applications of silica particles international journal of advanced. Eng Technol 4:249-255

Devine RA, Duraud J-P, Dooryhée E (2000) Structure and imperfections in amorphous and crystalline silicon dioxide. Wiley, New York

Ding X, Zhao J, Liu Y, Zhang H, Wang Z (2004) Silica nanoparticles encapsulated by polystyrene via surface grafting and in situ emulsion polymerization. Mater Lett 58(25):3126-3130. https:// doi.org/10.1016/j.matlet.2004.06.003 
Dong L, Peng H, Wang S, Zhang Z, Li J, Ai F, Zhao Q, Luo M, Xiong $\mathrm{H}$, Chen L (2014) Thermally and magnetically dual-responsive mesoporous silica nanospheres: preparation, characterization, and properties for the controlled release of sophoridine. J Appl Polymer Sci 131(13). https://doi.org/10.1002/app.40477

Douglas BE, Ho S-M (2006) Crystal structures of silica and metal silicates. Struct Chem Crystalline Solids, 233-278. https://doi. org/10.1007/0-387-36687-3_10

Dubey R, Rajesh Y, More M (2015) Synthesis and characterization of $\mathrm{SiO} 2$ nanoparticles via sol-gel method for industrial applications. Mater Today Proc 2(4-5):3575-3579. https://doi.org/10.1016/j. matpr.2015.07.098

Dhinasekaran D, Raj R, Rajendran AR, Purushothaman B, Subramanian B, Prakasarao A, Singaravelu G (2020) Chitosan mediated 5-Fluorouracil functionalized silica nanoparticle from rice husk for anticancer activity. Int J Biol Macromol 156:969-980. https ://doi.org/10.1016/j.ijbiomac.2020.04.098

Eurov DA, Kurdyukov DA, Kirilenko DA, Kukushkina JA, Nashchekin AV, Smirnov AN, Golubev VG (2015) Core-shell monodisperse spherical $\mathrm{mSiO} 2 / \mathrm{Gd} 2 \mathrm{O} 3: \mathrm{Eu} 3+@ \mathrm{mSiO} 2$ particles as potential multifunctional theranostic agents. J Nanopart Res 17(2):82. https://doi.org/10.1007/s11051-015-2891-y

Fanderlik I (2013) Silica glass and its application. Elsevier, Amsterdam

Fardad M (2000) Catalysts and the structure of SiO2 sol-gel films. J Mater Sci 35(7):1835-1841. https://doi.org/10.1023/A:10047 49107134

Faria K, Gurgel R, Holanda J (2012) Recycling of sugarcane bagasse ash waste in the production of clay bricks. J Environ Manage 101:7-12. https://doi.org/10.1016/j.jenvman.2012.01.032

Feng J, Chang D, Wang Z, Shen B, Yang J, Jiang Y, Ju S, He N (2014) A FITC-doped silica coated gold nanocomposite for both in vivo X-ray CT and fluorescence dual modal imaging. RSC Adv 4(94):51950-51959. https://doi.org/10.1039/c4ra09392e

Feng Q, Chen K, Ma D, Lin H, Liu Z, Qin S, Luo Y (2018) Synthesis of high specific surface area silica aerogel from rice husk ash via ambient pressure drying. Colloids Surf A 539:399-406. https:// doi.org/10.1016/j.colsurfa.2017.12.025

Finnie KS, Bartlett JR, Barbé CJ, Kong LJL (2007) Formation of silica nanoparticles in microemulsions. Langmuir 23(6):3017-3024. https://doi.org/10.1021/la0624283

Ganesan K, Rajagopal K, Thangavel K (2007) Evaluation of bagasse ash as supplementary cementitious material. Cement Concr Compos 29(6):515-524. https://doi.org/10.1016/j.cemconcomp .2007 .03 .001

Geetha D, Ananthiand A, Ramesh P (2016) Preparation and characterization of silica material from rice husk ash-an economically viable method. Res Rev J Pure Appl Phys 4(3):20-26

Gelperina S, Kisich K, Iseman MD, Heifets L (2005) The potential advantages of nanoparticle drug delivery systems in chemotherapy of tuberculosis. Am J Respir Crit Care Med 172(12):1487-1490

Gerber T, Himmel B (1986) The structure of silica glass. J NonCryst Solids 83(3):324-334. https://doi.org/10.1016/00223093(86)90245-0

Giddel M, Jivan A (2007) Waste to wealth, potential of rice husk in India a literature review, International conference on cleaner technologies and environmental Management PEC, Pondicherry, India

Gilmore JL, Yi X, Quan L, Kabanov AV (2008) Novel nanomaterials for clinical neuroscience. J NeuroImmune Pharmacol 3(2):83-94. https://doi.org/10.1007/s11481-007-9099-6

Gong J-L, Liang Y, Huang Y, Chen J-W, Jiang J-H, Shen G-L, Yu $\mathrm{R}-\mathrm{Q}$ (2007) $\mathrm{Ag} / \mathrm{SiO} 2$ core-shell nanoparticle-based surfaceenhanced Raman probes for immunoassay of cancer marker using silica-coated magnetic nanoparticles as separation tools.
Biosens Bioelectron 22(7):1501-1507. https://doi.org/10.1016/j. bios.2006.07.004

Goyal A, Kunio H, Hidehiko O (2007) Mandula. Properties and Reactivity of Sugarcane Bagasse Ash, Tottori University, Japan

Greasley SL, Page SJ, Sirovica S, Chen S, Martin RA, Riveiro A, Hanna JV, Porter AE, Jones JR (2016) Controlling particle size in the Stöber process and incorporation of calcium. J Colloid Interface Sci 469:213-223. https://doi.org/10.1016/j.jcis.2016.01.065

Greenwood N, Earnshaw A (1997) Chemistry of the elements, 2nd edn. Butterworth-Heinemann, Oxford. https://doi.org/10.1016/ b978-0-7506-3365-9.50005-5

Grün M, Lauer I, Unger KK (1997) The synthesis of micrometerand submicrometer-size spheres of ordered mesoporous oxide MCM-41. Adv Mater 9(3):254-257. https://doi.org/10.1002/ adma.19970090317

Gu L, Zhang A, Hou K, Dai C, Zhang S, Liu M, Song C, Guo XJM, Materials M (2012) One-pot hydrothermal synthesis of mesoporous silica nanoparticles using formaldehyde as growth suppressant. Microporous Mesoporous Mater 152:9-15. https:// doi.org/10.1016/j.micromeso.2011.11.047

Guo Q, Huang D, Kou X, Cao W, Li L, Ge L, Li J (2017) Synthesis of disperse amorphous $\mathrm{SiO} 2$ nanoparticles via sol-gel process. Ceram Int 43(1):192-196. https://doi.org/10.1016/j.ceram int.2016.09.133

Guo Z, Du Y, Liu X, Ng S-C, Chen Y, Yang Y (2010) Enantioselectively controlled release of chiral drug (metoprolol) using chiral mesoporous silica materials. Nanotechnology 21(16):165103. https://doi.org/10.1088/0957-4484/21/16/165103

Hagura N, Ogi T, Shirahama T, Iskandar F, Okuyama K (2011) Highly luminescent silica-coated $\mathrm{ZnO}$ nanoparticles dispersed in an aqueous medium. J Lumin 131(5):921-925. https://doi. org/10.1016/j.jlumin.2010.12.024

Hajarul AAW, Nor DZ, Aziz AA, Khairunisak AR (2011) Properties of amorphous silica entrapped isoniazid drug delivery system. Adv Mater Res 364:134-138

Hariharan V, Sivakumar G (2013) Studies on synthesized nanosilica obtained from bagasse ash. Int J Chem Tech Res 5(3):1263-1266

Henderson G, Baker DR (2002) Synchrotron radiation: earth, environmental and materials sciences applications. https://doi. org/10.1007/s00126-002-0329-9

Hoffmann F, Cornelius M, Morell J, Fröba M (2006) Silica-based mesoporous organic-inorganic hybrid materials. Angew Chem Int Ed 45(20):3216-3251. https://doi.org/10.1002/anie.20050 3075

Holden NE (2001) History of the origin of the chemical elements and their discoverers. Prepared for the 41st IUPAC General Assembly 29. https://doi.org/10.1515/ci.2001.23.5.129

Hossain SS, Mathur L, Roy P (2018) Rice husk/rice husk ash as an alternative source of silica in ceramics: a review. J Asian Ceram Soc 6(4):299-313. https://doi.org/10.1080/21870764.2018.15392 10

Hu J, Wang W, Yu R, Guo M, He C, Xie X, Peng H, Xue Z (2017) Solid polymer electrolyte based on ionic bond or covalent bond functionalized silica nanoparticles. RSC Adv 7(87):54986-54994. https://doi.org/10.1039/c7ra08471d

Hu W-Y, Liu H, Shao Y-Z (2015) Fluorescein isothiocyanate embedded silica spheres in gadolinium carbonate shells as novel magnetic resonance imaging and fluorescence bi-modal contrast agents. New J Chem 39(9):7363-7371. https://doi.org/10.1039/c5nj0 $0537 \mathrm{j}$

Huabcharoen P, Wimolmala E, Markpin T, Sombatsompop N (2017) Purification and characterization of silica from sugarcane Bagasse ash as a reinforcing filler in natural rubber composites. BioResources 12(1):1228-1245. https://doi.org/10.15376 /biores.12.1.1228-1245 
Huang HS, Chang KH, Suzuki N, Yamauchi Y, Hu CC, Wu KCW (2013) Evaporation-induced coating of hydrous Ruthenium oxide on mesoporous silica nanoparticles to develop highperformance supercapacitors. Small 9(15):2520-2526. https ://doi.org/10.1002/smll.201202786

Huang Q, Lin X, Lin C, Zhang Y, Hu S, Wei C (2015) A high performance electrochemical biosensor based on $\mathrm{Cu} 2 \mathrm{O}$-carbon dots for selective and sensitive determination of dopamine in human serum. RSC Adv 5(67):54102-54108. https://doi.org/10.1039/ c5ra05433h

Huang Y, Li SFY (2013) Electrocatalytic performance of silica nanoparticles on graphene oxide sheets for hydrogen peroxide sensing. J Electroanal Chem 690:8-12. https://doi.org/10.1016/j. jelechem.2012.11.041

Huang Y, Weng D, Han L, Wang Y, Liu K, Yan J, Lu J (2017) Synthesis and characterization of $\mathrm{MnO} 2 /$ Hollow mesoporous silica nanocomposite as electrode materials for application in supercapacitors. Nanosci Nanotechnol Lett 9(11):1639-1648. https ://doi.org/10.1166/nnl.2017.2534

Huang S-S, Tung MT, Huynh CD, Hwang B-J, Bieker PM, Fang C-C, Wu N-L (2019) Engineering rice husk into a high-performance electrode material through an ecofriendly process and assessing its application for lithium-ion sulfur batteries. ACS Sustain Chem Eng 7(8):7851-7861. https://doi.org/10.1021/acssu schemeng.9b00092

Hui N, Wang S, Xie H, Xu S, Niu S, Luo X (2015) Nickel nanoparticles modified conducting polymer composite of reduced graphene oxide doped poly (3, 4-ethylenedioxythiophene) for enhanced nonenzymatic glucose sensing. Sensors Actuators B Chem 221:606-613. https://doi.org/10.1016/j.snb.2015.07.011

Hwang AA, Lu J, Tamanoi F, Zink JI (2015) Functional nanovalves on protein-coated nanoparticles for in vitro and in vivo controlled drug delivery. Small 11(3):319-328. https://doi. org/10.1002/smll.201400765

Ibrahim IA, Zikry A, Sharaf MA (2010) Preparation of spherical silica nanoparticles: Stober silica. J Am Sci 6(11):985-989

Jang ES, Lee SY, Cha E-J, Sun I-C, Kwon IC, Kim D, Kim YI, Kim K, Ahn C-H (2014) Fluorescent dye labeled iron oxide/ silica core/shell nanoparticle as a multimodal imaging probe. Pharm Res 31(12):3371-3378. https://doi.org/10.1007/s1109 5-014-1426-Z

Javed M, Abbas SM, Siddiq M, Han D, Niu L (2018) Mesoporous silica wrapped with graphene oxide-conducting PANI nanowires as a novel hybrid electrode for supercapacitor. $\mathbf{J}$ Phys Chem Solids 113:220-228. https://doi.org/10.1016/j. jpcs.2017.10.037

Jin S-A, Poudyal S, Marinero EE, Kuhn RJ, Stanciu LA (2016) Impedimetric dengue biosensor based on functionalized graphene oxide wrapped silica particles. Electrochim Acta 194:422-430. https:// doi.org/10.1016/j.electacta.2016.02.116

Joshaghani A, Moeini MAJC, Materials B (2017) Evaluating the effects of sugar cane bagasse ash (SCBA) and nanosilica on the mechanical and durability properties of mortar. Constr Build Mater 152:818-831. https://doi.org/10.1016/j.conbuildmat.2017.07.041

Ju J, Chen W (2015) In situ growth of surfactant-free gold nanoparticles on nitrogen-doped graphene quantum dots for electrochemical detection of hydrogen peroxide in biological environments. Anal Chem 87(3):1903-1910. https://doi.org/10.1021/ac5041555

Kaempgen M, Chan CK, Ma J, Cui Y, Gruner G (2009) Printable thin film supercapacitors using single-walled carbon nanotubes. Nano Lett 9(5):1872-1876. https://doi.org/10.1021/n18038579

Kaliyan N, Morey RV (2010) Densification characteristics of corn cobs. Fuel Process Technol 91(5):559-565. https://doi.org/10.1016/j. fuproc.2010.01.001

Ke M, Wahab JA, Hyunsik B, Song K-H, Lee JS, Gopiraman M, Kim IS (2016) Allantoin-loaded porous silica nanoparticles/ polycaprolactone nanofiber composites: fabrication, characterization, and drug release properties. RSC Advances 6(6):45934600. https://doi.org/10.1039/c5ra22199d

Kim TG, An GS, Han JS, Hur JU, Park BG, Choi S-C (2017) Synthesis of size controlled spherical silica nanoparticles via sol-gel process within hydrophilic solvent. J Korean Ceram Soc 54(1):4954. https://doi.org/10.4191/kcers.2017.54.1.10

Klabunde K (2001) Introduction to the nanoworld. Nanoscale Mater Chem, 6-7.

Kobayashi Y, Imai J, Nagao D, Takeda M, Ohuchi N, Kasuya A, Konno M (2007) Preparation of multilayered silica-Gd-silica core-shell particles and their magnetic resonance images. Colloids Surf A 308(1-3):14-19. https://doi.org/10.1016/j.colsurfa.2007.05.024

Kobayashi Y, Matsudo H, Li T-t, Shibuya K, Kubota Y, Oikawa T, Nakagawa T, Gonda K (2016) Fabrication of quantum dot/silica core-shell particles immobilizing Au nanoparticles and their dual imaging functions. Appl Nanosci 6(3):301-307. https:// doi.org/10.1007/s13204-015-0440-8

Koch EC, Clément D (2007) Special materials in pyrotechnics: VI. Silicon-an old fuel with new perspectives. Propellants Explosives Pyrotechnics Int J Deal Sci Technol Asp Energetic Mater 32 (3):205-212. https://doi.org/10.1002/prep.200700021

Korzhinsky M, Tkachenko S, Shmulovich K, Steinberg G (1995) Native $\mathrm{Al}$ and $\mathrm{Si}$ formation. Nature 375(6532):544. https://doi. org/10.1038/375544a0

Kresge C, Leonowicz M, Roth WJ, Vartuli J, Beck J (1992) Ordered mesoporous molecular sieves synthesized by a liquid-crystal template mechanism. nature 359 (6397), 710. doi.org/https:// doi.org/10.1038/359710a0

Kumar S, Upadhyaya JS, Negi YS (2010) Preparation of nanoparticles from corn cobs by chemical treatment methods. BioResources $5(2): 1292-1300$

Kuswandi BJECL (2019) Nanobiosensor approaches for pollutant monitoring. Environ Chem Lett 17(2):975-990. https://doi. org/10.1007/s10311-018-00853-x

Lai C-Y, Trewyn BG, Jeftinija DM, Jeftinija K, Xu S, Jeftinija S, Lin VS-Y (2003) A mesoporous silica nanosphere-based carrier system with chemically removable CdS nanoparticle caps for stimuli-responsive controlled release of neurotransmitters and drug molecules. J Am Chem Soc 125(15):4451-4459. https:// doi.org/10.1021/ja0286501

Law W-C, Yong K-T, Roy I, Xu G, Ding H, Bergey EJ, Zeng H, Prasad PN (2008) Optically and magnetically doped organically modified silica nanoparticles as efficient magnetically guided biomarkers for two-photon imaging of live cancer cells. The Journal of Physical Chemistry C 112(21):7972-7977. https://doi. org/10.1021/jp712090y

Lee K, Moon H-Y, Park C, Kim OR, Ahn E, Lee SY, Park HE, Ihm S-H, Seung K-B, Chang K (2009) Magnetic resonance imaging of macrophage activity in atherosclerotic plaques of apolipoprotein E-deficient mice by using polyethylene glycolated magnetic fluorescent silica-coated nanoparticles. Curr Appl Phys 9(1):S15-S18. https://doi.org/10.1016/j.cap.2008.08.040

Liberman A, Mendez N, Trogler WC, Kummel AC (2014) Synthesis and surface functionalization of silica nanoparticles for nanomedicine. Surf Sci Rep 69(2):132-158. https://doi.org/10.1016/j. surfrep.2014.07.001

Lichtfouse E, Rullkötter J (1994) Accelerated transformation of organic matter below the silica transition zone in immature sediments from the Japan Sea. Org Geochem 21:517-523. https://doi. org/10.1016/0146-6380(94)90102-3

Lide DR (2004) Handbook of chemistry and physics, 85th edn. CRC, Boca Raton, pp 186-187

Liou T-H, Yang C-C (2011) Synthesis and surface characteristics of nanosilica produced from alkali-extracted rice husk ash. 
Mater Sci Eng B 176(7):521-529. https://doi.org/10.1016/j. mseb.2011.01.007

Liu C, Li F, Ma LP, Cheng HM (2010) Advanced materials for energy storage. Adv Mater 22(8):E28-E62

Liu X, Chen X, Yang L, Chen H, Tian Y, Wang Z (2016) A review on recent advances in the comprehensive application of rice husk ash. Res Chem Intermed 42(2):893-913. https://doi.org/10.1007/ s11164-015-2061-y

Liu Y, Ai K, Lu L (2012) Nanoparticulate X-ray computed tomography contrast agents: from design validation to in vivo applications. Acc Chem Res 45(10):1817-1827. https://doi.org/10.1002/ adma.200903328

Liu Y, Chen S-S, Wang A-J, Feng J-J, Wu X, Weng X (2016) An ultrasensitive electrochemical sensor for hydrazine based on AuPd nanorod alloy nanochains. Electrochim Acta 195:68-76. https:// doi.org/10.1016/j.electacta.2016.01.229

Lopez T, Ortiz E, Alexander-Katz R, Basaldella E, Bokhimi X (2009) Cortisol controlled release by mesoporous silica. Nanomed Nanotechnol Biol Med 5 (2), 170-177. https://doi.org/10.1016/j. nano.2008.08.002

Lunevich L, Sanciolo P, Smallridge A, Gray S (2016) Silica scale formation and effect of sodium and aluminium ions-29 Si NMR study. Environ Sci Water Res Technol 2(1):174-185. https://doi. org/10.1039/c5ew00220f

Luo X, Cao JJECL (2018) Discovery of nano-sized gold particles in natural plant tissues. Environ Chem Lett 16(4):1441-1448. https ://doi.org/10.1007/s10311-018-0749-0

Madrid R, Nogueira C, Margarido F (2012) Production and characterisation of amorphous silica from rice husk waste, WasteEng' 2012. In: Proceedings of the 4th international conference on engineering for waste and biomass valorisation 2012

Mahajan A, Gupta P (2020) Carbon-based solid acids: a review. Environ Chem Lett 18:299-314. https://doi.org/10.1007/s10311-01900940-7

Mandal A, Chakrabarty D (2011) Isolation of nanocellulose from waste sugarcane bagasse (SCB) and its characterization. Carbohyd Polym 86(3):1291-1299. https://doi.org/10.1016/j.carbp ol.2011.06.030

Manzano M, Aina V, Arean C, Balas F, Cauda V, Colilla M, Delgado M, Vallet-Regi M (2008) Studies on MCM-41 mesoporous silica for drug delivery: effect of particle morphology and amine functionalization. Chem Eng J 137(1):30-37. https://doi. org/10.1016/j.cej.2007.07.078

McMillan P (1984) Structural studies of silicate glasses and meltsapplications and limitations of Raman spectroscopy. Am Miner 69(7-8):622-644

Meena J, Gupta A, Ahuja R et al (2020) Inorganic nanoparticles for natural product delivery: a review. Environ Chem Lett. https:// doi.org/10.1007/s10311-020-01061-2

Meguid S, Elzaabalawy A (2020) Potential of combating transmission of COVID-19 using novel self-cleaning superhydrophobic surfaces: part I-protection strategies against fomites. Int J Mech Mater Des 16(3): 423-431. https://doi.org/10.1007/s10999-02009513-X

Mehdi YA, Itatahine A, Fizir M, Xiao D, Dramou P, He H (2018) Multifunctional core-shell silica microspheres and their performance in self-carrier decomposition, sustained drug release and fluorescent bioimaging. J Solid State Chem 263:148-156. https ://doi.org/10.1016/j.jssc.2018.04.024

Mei X, Chen D, Li N, Xu Q, Ge J, Li H, Lu J (2012) Hollow mesoporous silica nanoparticles conjugated with $\mathrm{pH}$-sensitive amphiphilic diblock polymer for controlled drug release. Microporous Mesoporous Mater 152:16-24. https://doi. org/10.1016/j.micromeso.2011.12.015
Miller JR, Simon P (2008) Electrochemical capacitors for energy management. Science Magazine 321(5889):651-652. https:// doi.org/10.1126/science.1158736

Mohanraj K, Kannan S, Barathan S, Sivakumar G (2012) Preparation and characterization of nano $\mathrm{SiO} 2$ from corn cob ash by precipitation method.

Mokhtar H, Ramlah M, Aida Isma M, Huda N (2016) Characterization on silica from waste sugarcane bagasse for membrane fabrication. Jurnal Teknologi 78(5-4):43-47. https://doi.org/10.11113 /jt.v78.8539

Moosa AA, Saddam BF (2017) Synthesis and characterization of nanosilica from rice husk with applications to polymer composites. Am J Mater Sci 7(6):223-231

Morimoto H, Minato M, Nakagawa T, Sato M, Kobayashi Y, Gonda K, Takeda M, Ohuchi N, Suzuki N (2011) X-ray imaging of newlydeveloped gadolinium compound/silica core-shell particles. J Sol-Gel Sci Technol 59(3):650. https://doi.org/10.1007/s1097 1-011-2540-6

Morin-Crini N, Fourmentin M, Fourmentin S, Torri G, Crini GJECL (2019) Synthesis of silica materials containing cyclodextrin and their applications in wastewater treatment. Environ Chem Lett 17(2):683-696. https://doi.org/10.1007/s10311-018-00818-0

Mozzi R, Warren B (1969) The structure of vitreous silica. J Appl Crystallogr 2(4):164-172. https://doi.org/10.1107/s002188986 9006868

Naqvi HJ, Saeed A, Umair A, Shah FH (2011) Precipitated silica from wheat husk. J Pakistan Instit Chem Eng 39(1):51-54

Novak F, Plumeré N, Schetter B, Speiser B, Straub D, Mayer HA, Reginek M, Albert K, Fischer G, Meyer C (2010) Redox-active silica nanoparticles. Part 4. Synthesis, size distribution, and electrochemical adsorption behavior of ferrocene-and (diamine) (diphosphine)-ruthenium (II)-modified Stöber silica colloidal particles. Journal of Solid State Electrochemistry 14 (2), 289303. https://doi.org/10.1007/s10008-009-0811-8

NPMCR (2019) Accessed on 6 March 2019. Available online: https:// agricoop.nic.in/sites/default/files/NPMCR_1.pdf.

Okoronkwo E, Imoisili P, Olusunle S (2013) Extraction and characterization of amorphous silica from corn cob ash by sol-gel method. Chem Mater Res 3(4):68-72

Okoronkwo EA, Imoisili PE, Olubayode SA, Olusunle SO (2016) Development of silica nanoparticle from corn cob ash. Adv Nanoparticles 5(02):135. https://doi.org/10.4236/anp.2016.52015

Oladeji J (2010) Fuel characterization of briquettes produced from corncob and rice husk resides. Pac J Sci Technol 11(1):101-106

Osipov A, Osipova L, Zainullina RJIJoS (2015) Raman spectroscopy and statistical analysis of the silicate species and group connectivity in cesium silicate glass forming system. Int J Spectroscopy, 1-15. https://doi.org/10.1155/2015/572840

Ow H, Larson DR, Srivastava M, Baird BA, Webb WW, Wiesner U (2005) Bright and stable core-shell fluorescent silica nanoparticles. Nano Lett 5(1):113-117. https://doi.org/10.1021/n10482478

Owoeye SS, Oji B, Aderiye J (2015) Effect of temperature, time and atmospheric condition on active silica extraction from Corn Cob ash. Int J Eng Technol Innovat 2:1-5

Pandey S, Mewada A, Thakur M, Pillai S, Dharmatti R, Phadke C, Sharon M (2014) Synthesis of mesoporous silica oxide/C-dot complex (meso-SiO 2/C-dots) using pyrolysed rice husk and its application in bioimaging. RSC Adv 4(3):1174-1179. https://doi. org/10.1039/c3ra45227a

Pauling L (1957) Discovery of the elements. ACS Publications, Mary Elvira. https://doi.org/10.1021/ed034p51.1

Peng H, Dong R, Wang S, Zhang Z, Luo M, Bai C, Zhao Q, Li J, Chen L, Xiong H (2013) A pH-responsive nano-carrier with mesoporous silica nanoparticles cores and poly (acrylic acid) shell-layers: fabrication, characterization and properties for 
controlled release of salidroside. Int J Pharm 446(1-2):153-159. https://doi.org/10.1016/j.ijpharm.2013.01.071

Pinho SL, Pereira GA, Voisin P, Kassem J, Bouchaud V, Etienne L, Peters JA, Carlos L, Mornet S, Geraldes CF (2010) Fine tuning of the relaxometry of $\gamma$-Fe2O3@ $\mathrm{SiO} 2$ nanoparticles by tweaking the silica coating thickness. ACS Nano 4(9):5339-5349. https:// doi.org/10.1021/nn101129r

Peng Z, Kong LX, Li S-D, Chen Y, Huang MFJCS (2007) Self-assembled natural rubber/silica nanocomposites: its preparation and characterization. Compos Sci Technol 67(15-16):3130-3139. https://doi.org/10.1016/j.compscitech.2007.04.016

Pode RJR, Reviews SE (2016) Potential applications of rice husk ash waste from rice husk biomass power plant. Renew Sustain Energy Rev 53:1468-1485. https://doi.org/10.1016/j. rser.2015.09.051

Prabha S, Durgalakshmi D, Aruna P, Ganesan SJV (2019) Influence of the parameters in the preparation of silica nanoparticles from biomass and chemical silica precursors towards bioimaging application. Vacuum 160:181-188. https://doi.org/10.1016/j. vacuum.2018.11.030

Qi D, Lin C, Zhao H, Liu H, Lü T (2017) Size regulation and prediction of the $\mathrm{SiO} 2$ nanoparticles prepared via Stöber process. J Dispersion Sci Technol 38(1):70-74. https://doi.org/10.1080/01932 691.2016.1143373

Qin X, Yin Y, Yu H, Guo W, Pei M (2016) A novel signal amplification strategy of an electrochemical aptasensor for kanamycin, based on thionine functionalized graphene and hierarchical nanoporous PtCu. Biosens Bioelectron 77:752-758. https://doi.org/10.1016/j. bios.2015.10.050

Rahman NA, Widhiana I, Juliastuti SR, Setyawan H (2015) Synthesis of mesoporous silica with controlled pore structure from bagasse ash as a silica source. Colloids Surf A 476:1-7. https:// doi.org/10.1016/j.colsurfa.2015.03.018

Rahmat N, Sabali MA, Sandu AV, Sahiron N, Sandu IG (2016) Study of calcination temperature and concentration of $\mathrm{NaOH}$ effect on crystallinity of silica from sugarcane Bagasse Ash (SCBA). Rev Chim 67(9):1872-1875

Ramadhansyah P, Salwa M, Mahyun A, Bakar BA, Johari MM, Norazman CCJPE (2012) Properties of concrete containing rice husk ash under sodium chloride subjected to wetting and drying. Proc Eng 50:305-313. https://doi.org/10.1016/j.proeng.2012.10.035

Rao KS, El-Hami K, Kodaki T, Matsushige K, Makino K (2005) A novel method for synthesis of silica nanoparticles. J Colloid Interface Sci 289(1):125-131. https://doi.org/10.1016/j. jcis.2005.02.019

Rastogi A, Tripathi DK, Yadav S, Chauhan DK, Živčák M, Ghorbanpour M, El-Sheery NI, Brestic MJB (2019) Application of silicon nanoparticles in agriculture. Biotech 9(3), 90. https://doi. org/10.1007/s13205-019-1626-7

Razo DAS, Pallavidino L, Garrone E, Geobaldo F, Descrovi E, Chiodoni A, Giorgis F (2008) A version of Stöber synthesis enabling the facile prediction of silica nanospheres size for the fabrication of opal photonic crystals. J Nanopart Res 10(7):1225-1229. https ://doi.org/10.1007/s11051-008-9373-4

Rezaei S, Manoucheri I, Moradian R, Pourabbas BJCEJ (2014) Onestep chemical vapor deposition and modification of silica nanoparticles at the lowest possible temperature and superhydrophobic surface fabrication. J Nanotechnol 252:11-16. https://doi. org/10.1016/j.cej.2014.04.100

Riaz S, Ashraf M, Hussain T, Hussain MTJC (2019) Modification of silica nanoparticles to develop highly durable superhydrophobic and antibacterial cotton fabrics. Cellulose 26(8):5159-5175. https://doi.org/10.1007/s10570-019-02440-x

Rodrigues A, Emeje M (2012) Recent applications of starch derivatives in nanodrug delivery. Carbohyd Polym 87(2):987-994. https:// doi.org/10.1016/j.carbpol.2011.09.044
Rossi LM, Shi L, Quina FH, Rosenzweig Z (2005) Stöber synthesis of monodispersed luminescent silica nanoparticles for bioanalytical assays. Langmuir 21(10):4277-4280. https://doi.org/10.1021/ la0504098

Saei AA, Dolatabadi JEN, Najafi-Marandi P, Abhari A, de la Guardia M (2013) Electrochemical biosensors for glucose based on metal nanoparticles. Trends Anal Chem 42:216-227. https://doi. org/10.1016/j.trac.2012.09.011

Sahoo SK, Labhasetwar V (2003) Nanotech approaches to drug delivery and imaging. Drug Discovery Today 8(24):1112-1120. https ://doi.org/10.1016/s1359-6446(03)02903-9

Saito G, Sasaki H, Takahashi H, Sakaguchi NJN (2018) Solutionplasma-mediated synthesis of Si nanoparticles for anode material of lithium-ion batteries. Nanomater Nanotechnol 8(5):286. https ://doi.org/10.3390/nano8050286

Salh R (2011) 'Defect related luminescence in silicon dioxide network: a review.' (InTech Rijeka) doi.org/https://doi.org/10.5772/22607

Santra S, Yang H, Dutta D, Stanley JT, Holloway PH, Tan W, Moudgil BM, Mericle RA (2004) TAT conjugated, FITC doped silica nanoparticles for bioimaging applications. Chem Commun 24:2810-2811. https://doi.org/10.1039/b411916a

Satvekar RK, Pawar SH (2018) Multienzymatic Cholesterol Nanobiosensor Using Core-Shell Nanoparticles Incorporated Silica Nanocomposite. J Med Biol Eng, 1-9. https://doi.org/10.1007/ s40846-017-0345-y

Saxena R, Adhikari D, Goyal H (2009) Biomass-based energy fuel through biochemical routes: a review. Renew Sustain Energy Rev 13(1):167-178. https://doi.org/10.1016/j.rser.2007.07.011

Shariff A, Aziz NSM, Ismail NI, Abdullah N (2016) Corn cob as a potential feedstock for slow pyrolysis of biomass. J Phys Sci 27(2):123. https://doi.org/10.21315/jps2016.27.2.9

Shim J, Velmurugan P, Oh B-T (2015) Extraction and physical characterization of amorphous silica made from corn cob ash at variable $\mathrm{pH}$ conditions via sol gel processing. J Ind Eng Chem 30:249-253. https://doi.org/10.1016/j.jiec.2015.05.029

Shyam M (2002) Agro-residue-based renewable energy technologies for rural development. Energy Sustain Dev 6(2):37-42. https:// doi.org/10.1016/s0973-0826(08)60311-7

Silva GA (2004) Introduction to nanotechnology and its applications to medicine. Surg Neurol 61(3):216-220. https://doi.org/10.1016/j. surneu.2003.09.036

Silviana S, Bayu WJ (2018) Silicon conversion from bamboo leaf silica by magnesiothermic reduction for development of Li-ion baterry anode, MATEC Web of Conferences'.2018 (EDP Sciences) doi. org/https://doi.org/10.1051/matecconf/201815605021

Simon P, Gogotsi Y (2010) Materials for electrochemical capacitors. In: Nanoscience and technology: a collection of reviews from nature journals. World Scientific, Singapore,pp 320-329 https:// doi.org/10.1142/9789814287005 0033

Singh L, Agarwal S, Bhattacharyya S, Sharma U, Ahalawat S (2011) Preparation of silica nanoparticles and its beneficial role in cementitious materials. Nanomater Nanotechnol 1(1):44-51. https://doi.org/10.5772/50950

Singh LP, Bhattacharyya SK, Kumar R, Mishra G, Sharma U, Singh G, Ahalawat S (2014) Sol-Gel processing of silica nanoparticles and their applications. Adv Coll Interface Sci 214:17-37. https ://doi.org/10.1016/j.cis.2014.10.007

Singh N, Karambelkar A, Gu L, Lin K, Miller JS, Chen CS, Sailor MJ, Bhatia SN (2011) Bioresponsive mesoporous silica nanoparticles for triggered drug release. J Am Chem Soc 133(49):1958219585. https://doi.org/10.1021/ja206998x

Singh RK, Patel KD, Kim J-J, Kim T-H, Kim J-H, Shin US, Lee E-J, Knowles JC, Kim H-W (2014) Multifunctional hybrid nanocarrier: magnetic CNTs ensheathed with mesoporous silica for drug delivery and imaging system. ACS Appl Mater Interfaces 6(4):2201-2208. https://doi.org/10.1021/am4056936 
Singh SKL, All Jawald S (2013) Utilization of sugarcane bagasse ash (SCBA) as pozzolanic material in concrete. A review, IJBSTR

Slowing II, Trewyn BG, Giri S, Lin VY (2007) Mesoporous silica nanoparticles for drug delivery and biosensing applications. Adv Func Mater 17(8):1225-1236. https://doi.org/10.1002/ adfm.200601191

Song J-T, Yang X-Q, Zhang X-S, Yan D-M, Yao M-H, Qin M-Y, Zhao Y-D (2015) Composite silica coated gold nanosphere and quantum dots nanoparticles for X-ray CT and fluorescence bimodal imaging. Dalton Trans 44(25):11314-11320. https://doi. org/10.1039/c5dt01286d

Song Q, Peng M, Wang L, He D, Ouyang J (2016) A fluorescent aptasensor for amplified label-free detection of adenosine triphosphate based on core-shell Ag@ SiO2 nanoparticles. Biosens Bioelectron 77:237-241. https://doi.org/10.1016/j. bios.2015.09.008

Sounderya N, Zhang Y (2008) Use of core/shell structured nanoparticles for biomedical applications. Recent Patents Biomed Eng 1(1):34-42. https://doi.org/10.2174/1874764710801010034

Shen Y, Zhao P, Shao Q (2014) Porous silica and carbon derived materials from rice husk pyrolysis char. Microporous Mesoporous Mater 188:46-76. https://doi.org/10.1016/j.micro meso.2014.01.005

Shimura N, Ogawa M (2007) Preparation of surfactant templated nanoporous silica spherical particles by the Stöber method. Effect of solvent composition on the particle size. J Mater Sci 42(14):5299-5306

Srinivasan K, Subramanian K, Rajasekar A, Murugan K, Benelli G, Dinakaran K (2017) A sensitive optical sensor based on DNAlabelled Si@SiO2 core-shell nanoparticle for the detection of $\mathrm{Hg} 2+$ ions in environmental water samples. Bull Mater Sci 40(7):1455-1462. https://doi.org/10.1007/s12034-017-1486-X

Stanley RA, Nesaraj AS (2014) Effect of surfactants on the wet chemical synthesis of silica nanoparticles. Int J Appl Sci Eng12:9-21. https://doi.org/10.6703/IJASE.2014.12(1).9

Stefanakis D, Ghanotakis D (2014) Synthesis and characterization of nanoparticles, consisting of a gadolinium paramagnetic core and a mesoporous silica shell, for controlled delivery of hydrophobic drugs. J Nanopart Res 16(1):2211. https://doi.org/10.1007/s1105 1-013-2211-3

Stöber W, Fink A, Bohn E (1968) Controlled growth of monodisperse silica spheres in the micron size range. J Colloid Interface Sci 26(1):62-69. https://doi.org/10.1016/0021-9797(68)90272-5

Sumathi R, Thenmozhi R (2016) Preparation of spherical silica nanoparticles by Sol-Gel method, II. In: International conference on systems, science, control, communication, engineering and technology

Suzuki K, Ikari K, Imai H (2004) Synthesis of silica nanoparticles having a well-ordered mesostructureusing a double surfactant system. J Am Chem Soc 126(2):462-463. https://doi.org/10.1021/ ja038250d

Tadanaga K, Morita K, Mori K, Tatsumisago M (2013) Synthesis of monodispersed silica nanoparticles with high concentration by the Stöber process. J Sol-Gel Sci Technol 68(2):341-345. https ://doi.org/10.1007/s10971-013-3175-6

Tan SY, Teh C, Ang CY, Li M, Li P, Korzh V, Zhao Y (2017) Responsive mesoporous silica nanoparticles for sensing of hydrogen peroxide and simultaneous treatment toward heart failure. Nanoscale 9(6):2253-2261. https://doi.org/10.1039/c6nr08869d

Tang J, Slowing II, Huang Y, Trewyn BG, Hu J, Liu H, Lin VS-Y (2011) Poly (lactic acid)-coated mesoporous silica nanosphere for controlled release of venlafaxine. J Colloid Interface Sci 360(2):488-496. https://doi.org/10.1016/j.jcis.2011.05.027
Tang L, Cheng J (2013) Nonporous silica nanoparticles for nanomedicine application. Nano Today 8(3):290-312. https://doi. org/10.1016/j.nantod.2013.04.007

Thomas M, Slipper I, Walunj A, Jain A, Favretto M, Kallinteri P, Douroumis D (2010) Inclusion of poorly soluble drugs in highly ordered mesoporous silica nanoparticles. Int J Pharm 387(12):272-277. https://doi.org/10.1016/j.ijpharm.2009.12.023

Todkar B, Deorukhar O, Deshmukh S (2016) Extraction of silica from rice husk. Int J Eng Res Dev 12:69-74

Trewyn BG, Slowing II, Giri S, Chen H-T, Lin VS-Y (2007) Synthesis and functionalization of a mesoporous silica nanoparticle based on the sol-gel process and applications in controlled release. Acc Chem Res 40(9):846-853. https://doi.org/10.1021/ar600032u

Tsai W, Chang C, Wang S, Chang C, Chien S, Sun H (2001) Cleaner production of carbon adsorbents by utilizing agricultural waste corn cob. Resour Conserv Recycl 32(1):43-53. https://doi. org/10.1016/s0921-3449(00)00093-8

Tyagi V, Pandit S, Sharma A, Gupta RK (2017) Extraction and characterization of silica from rice husk for use in food industries. Extraction 2(4)

Tzankov B, Yoncheva K, Lambov N (2014) Mesoporous silica nanoparticles as drug carriers. Pharmacia 61(1):27-37

Vallet-Regí M, Colilla M, González B (2011) Medical applications of organic-inorganic hybrid materials within the field of silicabased bioceramics. Chem Soc Rev 40(2):596-607. https://doi. org/10.1039/c0cs00025f

Vallet-Regí M, Balas F, Arcos D (2007) Mesoporous materials for drug delivery. Angew Chem Int Ed 46(40):7548-7558

Vansant EF, Van Der Voort P, Vrancken KC (1995) Characterization and chemical modification of the silica surface. Elsevier, Amsterdam. https://doi.org/10.1016/s0167-2991(06)81511-9

Vazquez NI, Gonzalez Z, Ferrari B, Castro Y (2017) Synthesis of mesoporous silica nanoparticles by sol-gel as nanocontainer for future drug delivery applications. Boletín de la Sociedad Española de Cerámica y Vidrio 56(3):139-145. https://doi. org/10.1016/j.bsecv.2017.03.002

Velmurugan P, Shim J, Lee K-J, Cho M, Lim S-S, Seo S-K, Cho K-M, Bang K-S, Oh B-T (2015) Extraction, characterization, and catalytic potential of amorphous silica from corn cobs by sol-gel method. J Ind Eng Chem 29:298-303. https://doi.org/10.1016/j. jiec.2015.04.009

Verma MLJECL (2017) Nanobiotechnology advances in enzymatic biosensors for the agri-food industry. Environ Chem Lett 15(4):555-560. https://doi.org/10.1007/s10311-017-0640-4

Viarbitskaya S, Ryderfors L, Mikaelsson T, Mukhtar E, Johansson LB-A (2011) Luminescence enhancement from silica-coated gold nanoparticle agglomerates following multi-photon excitation. J Fluores 21(1):257-264. https://doi.org/10.1007/s1089 5-010-0713-2

Vijayan R, Kumar GS, Karunakaran G, Surumbarkuzhali N, Prabhu S, Ramesh R (2020) Microwave combustion synthesis of tin oxidedecorated silica nanostructure using rice husk template for supercapacitor applications. J Mater Sci: Mater Electron, 1-8. https:// doi.org/10.1007/s10854-020-03142-y

Viswanathan S, Kovacs Z, Green KN, Ratnakar SJ, Sherry AD (2010) Alternatives to gadolinium-based metal chelates for magnetic resonance imaging. Chem Rev 110(5):2960-3018. https://doi. org/10.1021/cr900284a

Vivero-Escoto JL, Huang Y-T (2011) Inorganic-organic hybrid nanomaterials for therapeutic and diagnostic imaging applications. Int J Mol Sci 12(6):3888-3927. https://doi.org/10.3390/ijms1 2063888

Vu KB, Bach LG, Van Tran T, Thuong NT, Giang H, Bui QTP, Ngo STJCPL (2019) Gold@ silica catalyst: porosity of silica shells 
switches catalytic reactions. Chem Phys Lett 728:80-86. https:// doi.org/10.1016/j.cplett.2019.04.082

Waddell WH (2000) Silica, amorphous. Kirk-Othmer Encycl Chem Technol. https://doi.org/10.1002/0471238961.011315182301040 4.a01

Wan MM, Yang JY, Qiu Y, Zhou Y, Guan CX, Hou Q, Lin WG, Zhu JH (2012) Sustained release of heparin on enlarged-pore and functionalized MCM-41. ACS Appl Mater Interfaces 4(8):41134122. https://doi.org/10.1021/am300878z

Wang X-D, Shen Z-X, Sang T, Cheng X-B, Li M-F, Chen L-Y, Wang Z-S (2010) Preparation of spherical silica particles by Stöber process with high concentration of tetra-ethyl-orthosilicate. J Colloid Interface Sci 341(1):23-29. https://doi.org/10.1016/j. jcis.2009.09.018

Wassie AB, Srivastava VC', (2017) Synthesis and characterization of Nano-Silica from Teff Straw. J Nano Res (Trans Tech Publ). https ://doi.org/10.4028/www.scientific.net/jnanor.46.64

Winter M, Brodd RJ (2004) What are batteries, fuel cells, and supercapacitors? Chem Rev ACS Publ 104(10):4245-4270. https://doi. org/10.1021/cr020730k

Wu L, Zhou Y, Nie W, Song L, Chen P (2015) Synthesis of highly monodispersed teardrop-shaped core-shell $\mathrm{SiO} 2 / \mathrm{TiO} 2$ nanoparticles and their photocatalytic activities. Appl Surf Sci 351:320 326. https://doi.org/10.1016/j.apsusc.2015.05.152

Wu X, Wang Z, Zhu D, Zong S, Yang L, Zhong Y, Cui Y (2013) $\mathrm{pH}$ and thermo dual-stimuli-responsive drug carrier based on mesoporous silica nanoparticles encapsulated in a copolymerlipid bilayer. ACS Appl Mater Interfaces 5(21):10895-10903. https://doi.org/10.1021/am403092m

Wu S-H, Mou C-Y, Lin H-P (2013) Synthesis of mesoporous silica nanoparticles. Chem Soc Rev 42:3862-3875. https://doi. org/10.1039/C3CS35405A

Yanagisawa T, Shimizu T, Kuroda K, Kato C (1990) The preparation of alkyltriinethylaininonium-kaneinite complexes and their conversion to microporous materials. Bull Chem Soc Jpn 63(4):988992. https://doi.org/10.1246/bcsj.63.988

Yermekova Z, Mansurov Z, Mukasyan AJIJoS-PH-TS (2010) Combustion synthesis of silicon nanopowders. Int J Self Propag High Temp Synth 19(2):94-101. https://doi.org/10.3103/s106138621 0020032

Yogeswaran U, Chen S-M (2008) A review on the electrochemical sensors and biosensors composed of nanowires as sensing material. Sensors 8(1):290-313. https://doi.org/10.3390/s8010290

You B, Yang J, Sun Y, Su Q (2011) Easy synthesis of hollow core, bimodal mesoporous shell carbon nanospheres and their application in supercapacitor. Chem Commun 47(45):12364-12366. https://doi.org/10.1039/c1cc15348j

Yu C-H, Tam K, Tsang ES (2008) Chemical methods for preparation of nanoparticles in solution. Handbook Metal Phys 5:113-141

Yu K, Guo Y, Ding X, Zhao J, Wang Z (2005) Synthesis of silica nanocubes by sol-gel method. Mater Lett 59(29-30):4013-4015. https://doi.org/10.1016/j.matlet.2005.07.055
Yu T, Malugin A, Ghandehari H (2011) Impact of silica nanoparticle design on cellular toxicity and hemolytic activity. ACS Nano 5(7):5717-5728. https://doi.org/10.1021/nn2013904

Yuan J, Zhou S, Gu G, Wu L (2005) Encapsulation of organic pigment particles with silica via sol-gel process. J Sol-Gel Sci Technol 36(3):265-274. https://doi.org/10.1007/s10971-005-4063-5

Yuvakkumar R, Elango V, Rajendran V, Kannan N (2014) Highpurity nano silica powder from rice husk using a simple chemical method. J Exp Nanosci 9(3):272-281. https://doi. org/10.1080/17458080.2012.656709

Zainala NA, Shukor SRA, Wabb HAA, Razakb K (2013) Study on the effect of synthesis parameters of silica nanoparticles entrapped with rifampicin. Chem Eng Trans 32:2245-2250

Zakaria J, Shukor SRA, Zainal NA, Abdul K Production of silica nanoparticles entrapped with Rifampicin: effect of surfactant, stirring rate and water content.

Zeng D, Zhang H, Wang B, Sang K, Yang J (2015) Effect of ammonia concentration on silica spheres morphology and solution hydroxyl concentration in Stober process. J Nanosci Nanotechnol 15(9):7407-7411. https://doi.org/10.1166/jnn.2015.10595

Zemnukhova L, Kharchenko U, Beleneva I (2015) Biomass derived silica containing products for removal of microorganisms from water. Int J Environ Sci Technol 12(5):1495-1502. https://doi. org/10.1007/s13762-014-0529-8

Zhang Y, Gao F, Wanjala B, Li Z, Cernigliaro G, Gu ZJACBE (2016) High efficiency reductive degradation of a wide range of azo dyes by SiO2-Co core-shell nanoparticles. Appl Catal B 199:504-513. https://doi.org/10.1016/j.apcatb.2016.06.030

Zhao Y, Vivero-Escoto JL, Slowing II, Trewyn BG, Lin VS (2010) Capped mesoporous silica nanoparticles as stimuli-responsive controlled release systems for intracellular drug/gene delivery. Expert Opini Drug Delivery 7(9):1013-1029. https://doi. org/10.1517/17425247.2010.498816

Zhou Z, Zhang C, Qian Q, Ma J, Huang P, Pan L, Gao G, Fu H, Fu S, Song H (2013) Folic acid-conjugated silica capped gold nanoclusters for targeted fluorescence/X-ray computed tomography imaging. J Nanobiotechnol 11(1):17. https://doi. org/10.1186/1477-3155-11-17

Zhu T, Hu Y, Yang K, Dong N, Yu M, Jiang N (2018) A novel SERS nanoprobe based on the use of core-shell nanoparticles with embedded reporter molecule to detect E. coli O157: H7 with high sensitivity. Microchimica Acta 185(1), 30. https://doi. org/10.1007/s00604-017-2573-9

Publisher's Note Springer Nature remains neutral with regard to jurisdictional claims in published maps and institutional affiliations. 